\title{
Experimental and Numerical Studies of
}

\section{Fire Exposed Lipped Channel Columns subject to Distortional Buckling}

\author{
Shanmuganathan Gunalan ${ }^{1}$ and Mahen Mahendran ${ }^{2}$
}

\begin{abstract}
Cold-formed steel sections are commonly used in low-rise commercial and residential buildings. During fire events, cold-formed steel structural elements in these buildings are exposed to elevated temperatures. Hence after such events there is a need to determine the residual strength of these structural elements. However, only limited information is available in relation to the residual strength of fire exposed cold-formed steel members. This research is aimed at investigating the residual distortional buckling capacities of fire exposed cold-formed steel lipped channel sections. A series of compression tests of fire exposed, short lipped channel columns made of varying steel grades and thicknesses was undertaken in this research. Test columns were exposed to different elevated temperatures up to $800{ }^{\circ} \mathrm{C}$. They were then allowed to cool down at ambient temperature before they were tested to failure. Suitable finite element models of tested columns were also developed and validated using test results. The residual compression capacities of tested columns were predicted using the ambient temperature cold-formed steel design rules (AS/NZS 4600, AISI S100 and Direct Strength Method). Post-fire mechanical properties obtained from a previous study were used in this study. Comparison of results showed that ambient temperature design rules for compression members can be used to predict the residual compression capacities of fire exposed short or laterally restrained cold-formed steel columns provided the maximum temperature experienced by the columns can be estimated after a fire event. Such residual capacity assessments will allow structural and fire engineers to make an accurate prediction of the safety of buildings after fire events. This paper presents the details of these experimental and numerical studies and the results.
\end{abstract}

Keywords: Cold-formed steel structures, Post-fire mechanical properties, Exposed temperature, Distortional buckling

Corresponding author's email address: m.mahendran@qut.edu.au

1 - Research Associate, Science and Engineering Faculty, Queensland University of Technology, Brisbane, QLD 4000, Email: s.gunalan@,qut.edu.au

2 - Professor, Science and Engineering Faculty, Queensland University of Technology, Brisbane, QLD 4000, Email: m.mahendran@qut.edu.au 


\subsection{Introduction}

Cold-formed steel members are commonly used as load bearing studs in light gauge steel frame (LSF) walls. Inevitably, they can be exposed to fires as seen in Figure 1. Recent research has improved the understanding of the behaviour of LSF walls under fire conditions [1-5]. In practical applications, cold-formed steel studs are likely to be protected by plasterboards and insulations, resulting in studs being subject to a non-uniform temperature condition during a fire. However, if the maximum temperature of the thin-walled studs in LSF walls can be estimated in a fire event, their compression strength under fire conditions can be estimated by a uniform elevated temperature design method. Hence past research has used this simpler uniform elevated temperature design method in their research [6-16]. Light gauge cold-formed steel columns are susceptible to various buckling modes and their interactions, and hence exhibit a complex behaviour under fire conditions. Local and distortional buckling are the most common failure modes of short columns while flexural and flexural-torsional buckling are the most common failure modes of long columns. These buckling behaviours have been investigated at both ambient and elevated temperatures in [617] using both experimental and numerical studies. They showed that ambient temperature design methods can be used to predict the elevated temperature strengths of cold-formed steel columns reasonably well provided appropriately reduced mechanical properties [18] are used.

Following fire events, the gypsum plasterboards which protect LSF wall steel studs can be easily removed from the wall frames to inspect the damage caused by fire. The structural engineer has to then decide if the strength of the light gauge steel wall frame is still adequate for future use if lined with new plasterboards. The behaviour of structural steel members after a fire event has been adequately investigated [19-22]. However, the behaviour of cold-formed steel members after a fire event has not been investigated yet. There are also no design guidelines in $[23,24]$ for assessing fire exposed cold-formed steel members. As a result of this limited knowledge and understanding in this field, over-conservative decisions are likely to be made when evaluating the residual capacities of fire exposed cold-formed steel members.

In the event of a fire, the section and member load bearing capacities of steel members are mostly affected by the changes in their mechanical properties (yield strength, elastic modulus, and ultimate strength) of steel sections. Current design standards contain no information detailing the mechanical properties of cold-formed steels after being exposed to elevated 
temperatures. Post-fire mechanical properties of high strength structural steels (S460 and S690) were investigated by Qiang et al. [25], who proposed suitable predictive equations. On the other hand Outinen and Makelainen [26] conducted research on various structural steels and reported some post-fire mechanical properties of cold-formed steels. Hence recent research at the Queensland University of Technology investigated the post-fire mechanical properties of cold-formed steels [27] and developed suitable equations to predict the residual mechanical properties including their stress-strain curves after being exposed to elevated temperatures up to $800{ }^{\circ} \mathrm{C}$. Such knowledge of the residual mechanical properties as a function of exposed temperature in a fire will allow engineers to make important decisions in relation to the re-use of fire exposed cold-formed steel structural members and frames. Their decision will be based on the assumption that the residual member capacities are simply proportional to the reduction in their mechanical properties. This may not always be true. Post-fire mechanical property studies [27] showed that yield strength was reduced more than elastic modulus when exposed to elevated temperatures while there was improved ductility with increasing exposed temperature. Hence there is a need to investigate the residual capacities of cold-formed steel members subject to various buckling modes such as local and distortional buckling.

It is also not known whether the residual member capacities can be calculated using ambient temperature design rules with the measured post-fire mechanical properties of cold-formed steels in [27]. Therefore in this research detailed experimental studies were undertaken to investigate the distortional buckling behaviour of light gauge cold-formed steel compression members after being exposed to elevated temperatures. Suitable finite element models were then developed to simulate the behaviour of tested columns and were validated using test results. Ambient temperature design rules were modified by including the post-fire mechanical properties and their accuracy was investigated by using the test and finite element analysis results. The measured mechanical properties of cold-formed steels from [27] were used with both finite element analyses and ambient temperature design rules. This paper presents the details of this research and the results.

\subsection{Post-fire Mechanical Properties of Cold-formed Steels}

An experimental study was undertaken at the Queensland University of Technology to determine the residual mechanical properties of cold-formed steels after a fire event [27]. 
Tensile coupon tests were conducted on three steel grades and thicknesses (G300-1.00 mm, G500-1.15 $\mathrm{mm}$ and G550-0.95 $\mathrm{mm}$ ) to obtain their stress-strain curves and relevant mechanical properties (yield strength, Young's modulus, ultimate strength and ductility). Ten temperatures were selected in this study: 20, 300, 400, 500, 550, 600, 650, 700, 750 and 800 ${ }^{\circ} \mathrm{C}$. The cold-formed steel sheet became very soft at temperatures above $800{ }^{\circ} \mathrm{C}$ and hence temperatures beyond $800{ }^{\circ} \mathrm{C}$ were not considered.

Elastic modulus was calculated from the initial slope of the stress-strain curve. The post-fire reduction factor was then calculated as the ratio of the elastic modulus after being exposed to an elevated temperature $(T) E_{T}$ to that at ambient temperature $E$ given in Table 1. Test results from this study showed that steel grade had an influence on the elastic modulus reduction factors. Hence two separate sets of predictive equations were developed for low and high grade steels. There are two main regions in which the elastic modulus reduction factors vary linearly: $700-800{ }^{\circ} \mathrm{C}$ for low grade steels and $400-800{ }^{\circ} \mathrm{C}$ for high grade steels. Hence linear equations were developed for the two identified temperature regions to predict the elastic modulus reduction factors of low (Equation 1 (b)) and high grade steels (Equation 2 (b)) for exposed temperatures (Figure 2(a)).

Low Grade Steels

$\begin{array}{ll}E_{T} / E=1 & \text { for } 20 \leq T \leq 700^{\circ} \mathrm{C} \\ E_{T} / E=1.28-0.0004 T & \text { for } 700<T \leq 800^{\circ} \mathrm{C}\end{array}$

High Grade Steels
$E_{T} / E=1$
for $20 \leq T \leq 400^{\circ} \mathrm{C}$
$E_{T} / E=1.15-0.000375 T$
for $400<T \leq 800^{\circ} \mathrm{C}$

The yield strength reduction factors were calculated as the ratio of yield strength after being exposed to an elevated temperature $(T) f_{y, T}$, to that at ambient temperature $f_{y}$, given in Table 2 . The yield strength of low grade steel steadily decreased as the specimens were exposed to temperatures up to $650{ }^{\circ} \mathrm{C}$. After this temperature, it decreased linearly with respect to exposed temperature. Equations 3(a) and (b) present the proposed equations for the yield strength reduction factors of low grade steels. The reduction factors of high grade steels showed three main regions after $300{ }^{\circ} \mathrm{C}$ : two nonlinear regions $\left(300-500\right.$ and $\left.500-600{ }^{\circ} \mathrm{C}\right)$ 
and one linear region $\left(600-800{ }^{\circ} \mathrm{C}\right)$. Three equations were therefore developed to represent them. Equations 4(a) to (d) present the proposed equations for the yield strength reduction factors of high grade steels (Figure 2(b)).

Low Grade Steels

$f_{y T} / f_{y}=1.005-0.00024 T$

for $20 \leq T \leq 650^{\circ} \mathrm{C}$

$f_{y T} / f_{y}=2.02-0.0018 T$

for $650<T \leq 800^{\circ} \mathrm{C}$

High Grade Steels

$\begin{array}{ll}f_{y T} / f_{y}=1 & \text { for } 20 \leq T \leq 300^{\circ} \mathrm{C} \\ f_{y T} / f_{y}=-3.5 \times 10^{-6} T^{2}+2.15 \times 10^{-3} T+0.67 & \text { for } 300<T \leq 500^{\circ} \mathrm{C} \\ f_{y T} / f_{y}=3.8 \times 10^{-5} T^{2}-4.63 \times 10^{-2} T+14.52 & \text { for } 500<T \leq 600^{\circ} \mathrm{C} \\ f_{y T} / f_{y}=0.63-0.00035 T & \text { for } 600<T \leq 800^{\circ} \mathrm{C}\end{array}$

\subsection{Experimental Study}

This experimental study was conducted to investigate the behaviour of cold-formed steel compression members subject to distortional buckling at ambient and exposed temperatures up to $800{ }^{\circ} \mathrm{C}$. Cold-formed steel specimens were heated up to the required temperature and then allowed to cool down at ambient temperature. An axial compressive load was applied thereafter at a constant rate until failure.

\subsection{Test Specimens}

Three lipped channel sections with a suitable length were selected based on the available literature, and our elastic buckling analyses using a finite strip analysis program CUFSM and a finite element program ABAQUS to ensure the occurrence of distortional buckling during the compression tests. The lipped channel sections used in this study were $40 \mathrm{~mm} \times 40 \mathrm{~mm} \times$ $5 \mathrm{~mm}$ with thicknesses of $0.95,1.0$ and $1.15 \mathrm{~mm}$ and a clear column height of $300 \mathrm{~mm}$. Additional lengths of $10 \mathrm{~mm}$ were provided at each end to allow for the fixing of specimens to the end plates. Cold-formed steel members are available in both low and high strength grades. Therefore one low strength (G300-1.00 mm) and two high strength (G500-1.15 mm and G550-0.95 mm) grades were selected with the chosen thicknesses. Eight exposed temperatures $\left(400,500,550,600,650,700,750\right.$ and $\left.800{ }^{\circ} \mathrm{C}\right)$ were selected to investigate the post-fire behaviour of the chosen lipped channel section columns. Hence a total of nine steel 
columns from each grade were tested at ambient temperature and after being exposed to elevated temperatures. In this study, cold-formed steel specimens heated up to $900{ }^{\circ} \mathrm{C}$ deformed under their own self weight and hence were not considered further in this investigation.

\subsection{Test Procedure}

External dimensions and thicknesses of test specimens were measured using a vernier calliper and a micrometer screw gauge, respectively (Table 3). It is common practice to use the base metal thickness in structural calculations. The base metal thickness was obtained by removing the coating of cold-formed steel specimens by immersing them in diluted hydrochloric acid. Thickness measurements were taken at three locations for each specimen. Table 3 gives the average base metal thickness and the cross-sectional dimensions of 27 test specimens. All the specimens were labelled according to the grade, nominal thickness and exposed temperature as shown in the table.

An electric furnace shown in Figure 3 was used in this experimental study to achieve the desired temperature. The thermocouple located inside the furnace gave the air temperature of the furnace on the display. Two additional thermocouples were placed inside the furnace to measure the temperature independently. The specimens were placed inside the furnace and the furnace temperature was increased to a temperature $50{ }^{\circ} \mathrm{C}$ less than the pre-selected value using a heating rate of $10-20{ }^{\circ} \mathrm{C} / \mathrm{min}$. After reaching this temperature, it was left for 15 minutes to ensure a uniform temperature distribution. The furnace was then set to a temperature $10{ }^{\circ} \mathrm{C}$ less than the target and left again for 15 minutes. Finally the furnace was set to the desired temperature and left for an additional 20 - 30 minutes. This method was followed to prevent any over-shooting of temperature beyond the target value. The specimens were then removed from the furnace and placed on a tray to air cool at its own rate.

All the tests were carried out using fixed-end supports. To achieve this support condition, special end plates were made to fit into the ends of the specimens (Figure 4). The end plates were fabricated from two thicknesses of steel plate, a $20 \mathrm{~mm}$ thick base plate and a $10 \mathrm{~mm}$ thick top plate. The two plates were cut to an approximate diameter of $100 \mathrm{~mm}$ and were bolted together using 4 M5 bolts. The top plate also featured a cut-out of the column profile with a clearance of $10 \mathrm{~mm}$ either side, to allow the grout to settle and form a strong bond 
around the end of the column member. The split base plate design also allowed the base plates to be unbolted after the completion of the test, thus facilitating easy removal of hardened grout. The specimen was placed in the grove, which was filled with procreate coil grout mixed with water. This grout fully hardened within 24 hours and prevented the columns against any movement at both ends. The centroid axes of the end plates and the specimen cross-section were kept the same while also keeping the two end plates horizontal and parallel to each other. Such arrangements allowed the application of compression load uniformly through the end plates. The compression tests were conducted using a $300 \mathrm{kN}$ Instron testing machine as shown in Figure 5.

During the tests, axial shortening and out-of-plane displacements of specimens were recorded in addition to the applied load. Out-of-plane displacements were measured at the middle of test specimens using laser LVDTs directed towards the web and flange elements. Axial shortening of the specimens was measured using the cross-head movement of the machine. All the LVDTs and the load channel were connected to a data logger system. Figures 6 (a) and (b) show the typical axial compression load versus deflection curves for G300-1.00 mm and G500-1.15 mm steel specimens, respectively, for an exposed temperature of $800{ }^{\circ} \mathrm{C}$. Table 4 presents the ultimate load for each test specimen.

\subsection{Observations and Results}

In general visual observations showed that there was a direct relationship between oxide level increase on the specimens and exposed temperatures (see Figure 7). This was also confirmed by using a thickness gauge to measure the oxide thickness. Specimens exposed to temperatures of $700{ }^{\circ} \mathrm{C}$ and above were found to have a heavy build-up of oxides.

In the tests the flanges began to deflect out-of-plane first near the column mid-height when the applied load approached the ultimate load. This was soon followed by rapid flange deformations until the specimen reached its ultimate load. All the specimens failed by distortional buckling as shown in Figure 8. Generally two different distortional buckling modes occurred depending on the initial geometric imperfection: both flanges moved inward or outward. The ultimate failure loads were recorded during the tests and are given in Table 4. Figure 9 shows the axial compression load versus axial shortening graphs of all the test specimens for ambient and different exposed temperatures. 
The ultimate load results $\left(P_{u}\right)$ from this study are plotted using a non-dimensional format in Figure 10, where the non-dimensional slenderness $\lambda$ is defined as $\sqrt{\frac{f_{y T}}{f_{c r T}}}$ where $f_{y T}$ and $f_{c r T}$ are the yield and elastic distortional buckling strengths, respectively, and $P_{y}$ is the squash load for exposed temperature $T$. The post-fire mechanical properties in Tables 1 and 2 are used in this study. As seen in Figure 10, the sections selected in this research have a slenderness between 0.75 and 1.5, i.e. the inelastic regime. Hence a numerical study was also conducted on the post-fire distortional buckling behaviour of cold-formed steel columns to extend the results to the elastic post-buckling regime.

The ultimate loads of different steel grade specimens are compared for ambient and exposed temperatures in Figure 11 which shows that the ultimate loads decrease with increasing exposed temperatures. Although a slight increase in ultimate loads occurred in some tests, this was considered to be due to minor experimental variations within a reasonable range. The ultimate loads were also compared with respect to the squash load. According to these figures, both low and high grade steel columns show a considerable difference between the ultimate $\left(P_{u}\right)$ and squash $\left(P_{y}\right)$ loads at lower exposed temperatures. However, when the exposed temperature was increased, the difference between these loads decreased rapidly.

\subsection{Finite Element Modelling}

\subsection{Selection of Element Type and Size}

In this research ABAQUS Standard Version 6.7 was used in the finite element analyses (FEA) of fire exposed cold-formed steel compression members subject to distortional buckling. Numerous shell element types are available in the finite element simulation using ABAQUS including S4, S4R, S4R5, S8R5 and S9R5. All these element types were considered in the simulation of cold-formed steel columns reported in Gunalan et al. [14] in order to select the most suitable element type. It was found that for small models (short columns subjected to local or distortional buckling modes) the differences in processing time and memory requirement are not significant. Therefore S4 element type was selected since it is a fully integrated, general-purpose shell element available in ABAQUS standard. 
Element size of the model is also an important factor in FEA. Finer mesh gives more accurate results at the expense of increased memory and processing time requirements. Therefore a convergence study was conducted in Gunalan et al. [14] for short cold-formed steel columns with various mesh sizes from $1 \mathrm{~mm} \times 1 \mathrm{~mm}$ to $9 \mathrm{~mm} \times 9 \mathrm{~mm}$ to determine the optimum element size. It was found that the optimum element size is $3 \mathrm{~mm} \times 3 \mathrm{~mm}$ and hence this element size was used in this research (Figure 12). The approximate lip length of the columns considered in this research is $5 \mathrm{~mm}$. Hence the lip was divided into three elements to obtain more accurate results.

\subsection{Loading and Boundary Conditions}

For accurate simulations it is important to use appropriate boundary conditions that reflect the end supports used in the experimental tests where both ends of the test columns were fixed against rotations and translations except that the bottom end was allowed to move axially. Hence in the numerical study also fixed support conditions were simulated and only axial translation at the bottom end was allowed as shown in Figure 12. These end boundary conditions allowed the specimens to fail symmetrically about the plane perpendicular to the axis of the column at mid-height. Due to the symmetry conditions of test specimen and loading, it is economical to simulate one half length of the test columns in the analyses. Therefore a half-length model was used with appropriate boundary conditions as shown Figure 12.

All three rotations were restrained at the bottom end of the column. This end of the column was also restrained in the two major directions (UX and UY) while the axial compressive load was applied at the section centroid. These boundary conditions were applied to the independent node of the rigid fixed MPC (Multi-Point Constraint). Dependent nodes are connected to the independent node using rigid beams and all the six structural degrees of freedoms are rigidly attached to each other. In this model, the independent node was located at the geometric centre of the cross-section. Dependent nodes are the perimeter nodes at the end surface of the model. Since the element size was selected as $3 \mathrm{~mm}$ x $3 \mathrm{~mm}$, the distance between the dependent nodes was small. Hence this MPC acted as a rigid surface that was rigidly connected to the end of the columns. The load was applied to the independent node at the geometric centre of the rigid fixed MPC located at the upper end (Figure 12). At the other 
end of the model (ie. column mid-height), out of plane displacements were allowed but the axial displacement was restrained. In addition, twist rotation was allowed but other two rotations about $\mathrm{X}$ and $\mathrm{Y}$ axes were restrained.

\subsection{Geometric Imperfections and Residual Stresses}

Geometric imperfections of light gauge cold-formed steel members play a vital role in FEA. It is important to include these imperfections in nonlinear analyses to initiate the appropriate buckling deformations. The geometric imperfection value is higher in cold-formed steel members in comparison to their small thicknesses. Therefore the ultimate load is significantly affected by geometric imperfections. In this research the section thickness $(t)$ was used as the imperfection value for thin cold-formed lipped channels based on [10]. The residual stress model proposed by Ranawaka and Mahendran [13] was used in Gunalan et al. [14] in the finite element analyses of lipped channel columns. However, the difference between the ultimate load capacities obtained with and without residual stresses was less than $1 \%$. Hence it was decided to ignore the effect of residual stresses in this research.

\subsection{Mechanical Property Model}

Mechanical properties are characterized by elastic modulus, stress-strain relationship and Poisson's ratio. An elastic-perfect plastic material model was used in FEA which assumes a constant yield strength in the plastic range. The measured ambient and post-fire temperature mechanical properties of G300-1.00, G500-1.15 and G550-0.95 mm thick cold-formed steels were obtained from Gunalan and Mahendran [27]. Tables 1 and 2 give the mechanical property values for these selected steel thicknesses and strength grades.

\subsection{Analysis Methods}

Test specimens were analysed to determine the elastic buckling and ultimate loads. MSC/PATRAN was used as a pre-processor to create the input files and as a post-processor to read the results. Two types of analyses were conducted using ABAQUS. Elastic buckling analyses were used to determine the elastic buckling loads and modes while nonlinear analyses were used to determine the ultimate loads and deformations. Initial geometric imperfections were included into the appropriate eigen buckling mode obtained from elastic buckling analyses. Nonlinear analyses were conducted using the modified Riks method to find the ultimate compression load. 


\subsection{Validation of Finite Element Models}

It is important to validate the developed finite element model to determine whether it can simulate the desired buckling and ultimate strength behaviour of cold-formed steel columns. For this purpose, finite element models of 27 tested specimens at ambient and after being exposed to elevated temperatures were developed. These models consisted of three grades and thicknesses (G300-1.00, G500-1.15 and G550-0.95 mm) and nine temperatures $(20,400$, $500,550,600,650,700,750$ and $\left.800{ }^{\circ} \mathrm{C}\right)$. They were validated using the ultimate loads and failure modes from tests and FEA. Due to an experimental recording error, test results of G550-0.95-700 specimen (Test 25) could not be used in this comparison (Table 4). The developed finite element model was validated by comparing the ultimate loads obtained from tests and FEA for different steel grades and thicknesses (Table 4). This table also presents the mean value (1.019) and the associated coefficient of variation (0.082) for the ratio of ultimate loads from test and FEA, which indicates a reasonably good agreement between test and FEA results. Accuracy of the developed models was also assessed by comparing the failure modes from FEA and tests. Figures 13(a) and (b) show the typical failure mode observed in the tests and compare it with the corresponding failure mode from FEA. These figures show that the failure modes from FEA and test are similar, ie. distortional buckling mode. In summary, by considering the ultimate loads and failure modes, it can be concluded that the developed finite element models are able to accurately simulate the distortional buckling behaviour of cold-formed steel compression members exposed to elevated temperatures. The use of accurate post-fire mechanical properties was a critical factor contributing to such accurate simulations.

\subsection{Comparison of Test and FEA Results with Predictions from the Current Design Standards}

In this section, the ultimate loads obtained from the tests and FEA were compared with the predictions from the available design equations for cold-formed steel structures (AS/NZS 4600 [28], AISI S100 [29] and Direct Strength Method (DSM) [30]) and the measured postfire mechanical properties reported in Tables 1 and 2 . The statistical model recommended by AISI S100 [29] was used to determine the capacity reduction factors for the values obtained from the current design rules [28-30]. AS/NZS 4600 [28] recommends a capacity reduction factor of 0.85 for compression members. 


\subsection{AS/NZS 4600 [28] and AISI S100 [29]}

AS/NZS 4600 and AISI S100 give identical design rules for distortional buckling and hence only AS/NZS 4600 design rules are discussed in this paper. Lau and Hancock [31] developed Equation 5(a) whereas Kwon and Hancock [32] developed Equation 5(b) to extend Lau and Hancock's curve for slender sections which buckle in the distortional mode in the postbuckling range. Hence when singly symmetric lipped channel sections are subjected to distortional buckling effects, after being exposed to an elevated temperature $T$, the residual ultimate load $P_{n T}$ can be obtained as follows,

$$
\begin{array}{ll}
P_{n T}=A f_{y T}\left(1-\frac{f_{y T}}{4 f_{o d T}}\right) & \text { for } \quad f_{o d T}>f_{y T} / 2 \\
P_{n T}=A f_{y T}\left[0.055\left(\sqrt{\frac{f_{y T}}{f_{o d T}}}-3.6\right)^{2}+0.237\right] \quad \text { for } \quad f_{y T} / 13 \leq f_{o d T} \leq f_{y T} / 2
\end{array}
$$

where $A$ is the area of the gross cross-section; $f_{y T}$ and $f_{o d T}$ are the yield and elastic distortional buckling strength of the specimen after being exposed to an elevated temperature $T$.

Table 4 compares the ultimate loads from tests and FEA with the predicted ultimate loads from Equations 5(a) and (b) of AS/NZS 4600 for the cold-formed lipped channel sections exposed to elevated temperatures. The measured yield strength and elastic modulus values $\left(f_{y T}\right.$ and $\left.E_{T}\right)$ given in Tables 1 and 2 were used in the calculations. The elastic distortional buckling strength $f_{\text {odT }}$ was determined from finite element analyses. The mean value of the ratio between the test and AS/NZS 4600 predicted ultimate loads is 1.068 while the associated COV and capacity reduction factor are 0.093 and 0.938 , respectively, for coldformed lipped channel sections considered in this study. The corresponding values for the comparison between FEA and AS/NZS 4600 predicted ultimate loads are 1.040, 0.039 and 0.951, which shows a better agreement than with tests as expected. Figure 10 shows that test and FEA results agreed well with AS/NZS 4600 predictions for fire exposed columns subject to distortional buckling. Therefore it can be concluded that AS/NZS 4600 design rules for distortional buckling can be conservatively used to predict the ultimate loads of fire exposed lipped channel sections. 
The accuracy of AS/NZS 4600 design rules in the post-buckling regime (Equation 5(b) proposed by Kwon and Hancock [32]) was further investigated by considering slender coldformed steel sections in a FEA based parametric study. Two sections shown in Figure 14 including Section 1 that was used in our tests were considered in the parametric study with G300-1.00 mm, G500-1.15 mm and G550-0.95 steels. Small stiffeners were used in the web and flange elements of Section 2 to eliminate local buckling of these columns. Three steel grades and thicknesses (G300-1.00, G500-1.15 and G550-0.95) and eight different exposed temperatures $\left(400,500,550,600,650,700,750\right.$ and $\left.800{ }^{\circ} \mathrm{C}\right)$ were considered. In the analyses the nominal yield strengths $(300 \mathrm{MPa}, 500 \mathrm{MPa}$ and $550 \mathrm{MPa})$ were used with an elastic modulus of $200000 \mathrm{MPa}$ at ambient temperature. The post-fire mechanical properties were predicted using Equations 1 to 4. Figure 15 shows that these FEA results closely agreed with AS/NZS 4600 predictions in the post-buckling regime for fire exposed columns subject to distortional buckling.

\subsection{Direct Strength Method}

The DSM proposed by Schafer [30] is one of the alternative methods to determine the strength of cold-formed steel members. It includes the distortional buckling of cold-formed steel compression members. Therefore its predictions were compared with test and FEA results from this research. Equations 6(a) and (b) give the ultimate loads of compression members subject to distortional buckling after being exposed to an elevated temperature $T$.

$$
\begin{aligned}
& P_{n T}=A f_{y T} \\
& \text { for } \quad \lambda \leq 0.561 \\
& P_{n T}=A f_{y T}\left[1-0.25\left(\frac{f_{o d T}}{f_{y T}}\right)^{0.6}\right]\left[\frac{f_{o d T}}{f_{y T}}\right]^{0.6} \quad \text { for } \quad \lambda>0.561 \\
& \text { with } \lambda=\sqrt{\frac{f_{y T}}{f_{o d T}}} \text { where } A, f_{y T} \text { and } f_{o d T} \text { are defined previously. }
\end{aligned}
$$

Table 4 and Figure 10 show the comparison of test and FEA results with Equations 6(a) and (b) predictions. The mean value of the experimental to predicted ultimate load ratio is 1.041 while the associated COV and capacity reduction factor are 0.096 and 0.911 , respectively, for cold-formed lipped channel sections considered in this study. Hence it can be concluded that the DSM design rules are able to predict the ultimate strengths of compression members, 
which failed in distortional buckling after being exposed to elevated temperatures. Figure 15 shows that the FEA results from the parametric study agreed well with DSM predictions in the post-buckling regime for fire exposed columns subject to distortional buckling.

\subsection{Estimation of Residual Column Strength}

The residual ultimate load ratio was calculated as the ratio of the ultimate load of lipped channel column after being exposed to an elevated temperature $(T) P_{u T}$, to that at ambient temperature $\mathrm{P}_{u}$. Figures 16(a) and (b) show the variation of this ratio with respect to different exposed temperatures. The plots were based on the FEA results obtained from the parametric study for Sections 1 and 2 (Figure 14). It should be noted that low grade steel predictions are based on G300-1.00 steel sections while high grade steel predictions are based on the average results obtained for G500-1.15 mm and G550-0.95 steel sections. The reduction in ultimate load follows a similar trend to that of the reduction in yield strength. This is expected as the reduction in elastic modulus is less than $15 \%$ even when exposed to $800{ }^{\circ} \mathrm{C}$ for low and high grade steels (Figure 2(a)). However, the reduction in ultimate load was less than the reduction in yield strength for both low and high grade steels as shown in Figures 16 (a) and (b).

The residual distortional buckling strength of low grade steel columns steadily decreased as the specimens were exposed to temperatures up to $650{ }^{\circ} \mathrm{C}$. After this temperature, it decreased linearly with respect to exposed temperature. Equations 7(a) and (b) present the proposed equations for the residual distortional buckling strength factors of low grade steel columns. These equations represent the temperature values ranging from 20 to $800{ }^{\circ} \mathrm{C}$ where $T$ is the exposed temperature in ${ }^{\circ} \mathrm{C}$ and $L R$ is the load ratio. Similarly a new set of equations, (Equations 8(a) to (d)) was developed to determine the residual distortional buckling strength factors of high grade steel columns by considering the FEA results obtained from this study. The residual (or reduction) factors of high grade steel columns show three main regions after $300{ }^{\circ} \mathrm{C}$ : two nonlinear regions $\left(300-500\right.$ and $\left.500-600{ }^{\circ} \mathrm{C}\right)$ and one linear region $\left(600-800{ }^{\circ} \mathrm{C}\right)$ and hence three equations were developed to represent them.

Low Grade Steel Columns

$$
\begin{array}{ll}
L R=1.003-1.587 \times 10^{-4} \mathrm{~T} & \text { for } 20 \leq T \leq 650^{\circ} \mathrm{C} \\
L R=1.896-1.533 \times 10^{-3} \mathrm{~T} & \text { for } 650<T \leq 800^{\circ} \mathrm{C}
\end{array}
$$


High Grade Steel Columns

$$
\begin{array}{ll}
L R=1 & \text { for } 20 \leq T \leq 300^{\circ} \mathrm{C} \\
L R=-3 \times 10^{-6} T^{2}+1.9 \times 10^{-3} T+0.7 & \text { for } 300<T \leq 500^{\circ} \mathrm{C} \\
L R=3 \times 10^{-5} T^{2}-3.67 \times 10^{-2} T+11.75 & \text { for } 500<T \leq 600^{\circ} \mathrm{C} \\
L R=0.77-4 \times 10^{-4} \mathrm{~T} & \text { for } 600<T \leq 800^{\circ} \mathrm{C}
\end{array}
$$

Eurocode 3 Part 1.2 [24] recommends a limiting temperature value of $350{ }^{\circ} \mathrm{C}$ for the fire design of cold-formed steel members irrespective of the load ratio. If cold-formed steel columns are subjected to a fire event where the maximum temperature was less than $350{ }^{\circ} \mathrm{C}$ as suggested by Eurocode 3 Part 1.2, then these columns can be assumed to retain $95 \%$ of their original capacities (Figures 16(a) and (b)). Experimental results have shown that coldformed steel columns can regain $90 \%$ of the original distortional buckling capacities if they are exposed to temperatures below $500{ }^{\circ} \mathrm{C}$. If the exposed temperature of a column in a fire is known, then Figures 16(a) and (b) can be used to obtain its residual capacity. For example, the load ratios of low and high grade steel columns that were exposed to a temperature of 700 ${ }^{\circ} \mathrm{C}$ were predicted as 0.82 and 0.49 , respectively, as shown in the figures. Alternatively Equations 7 and 8 or AS/NZS 4600 and DSM design rules (Equations 5 and 6) with appropriately reduced post-fire mechanical properties (Equations 1 to 4 ) can be used to predict the residual capacities of cold-formed steel columns, if the maximum exposed temperature can be estimated. The use of post-fire mechanical properties alone is also adequate as it provides conservative results as seen in Figures 16(a) and (b).

\subsection{Distortional Buckling Behaviour at Elevated Temperatures and After Cooling Down}

Figures 17(a) and (b) show the variation of residual ultimate load ratios at elevated temperatures and after cooling down for low and high grade steel sections, subject to distortional buckling. The FEA results of lipped channel columns at elevated temperatures from Ranawaka and Mahendran [13] and our research results are plotted in these figures. It should be noted that the high grade steel load ratios at elevated temperatures are based on the average FEA results obtained for G550-0.6 mm, G550-0.8 mm and G550-0.95 $\mathrm{mm}$ steel sections and low grade steel load ratios are based on the average test results obtained for G250-0.6 mm, G250-0.8 mm and G250-0.95 mm steel sections. 
The load ratios at elevated temperatures based on [13] emphasize that further research is not required for exposed temperatures beyond $800{ }^{\circ} \mathrm{C}$ (the capacity is less than $10 \%$ ). Coldformed steel columns would have distorted heavily or failed at these higher elevated temperatures and hence should be replaced.

Figures 17(a) and (b) clearly indicate the recovery of compression capacity of cold-formed steel members after they cool down to ambient temperature. The regain of strength increased with higher temperatures and the maximum regain of $60 \%$ and $40 \%$ were obtained for low and high grade steel columns, respectively. The regain of column strength was higher for low grade steel columns compared to high grade steel columns when they cool down to ambient temperatures as shown in Figures 17(a) and (b).

Figures 17(a) and (b) also show that the capacity of cold-formed steel column is significantly reduced when it is exposed to elevated temperatures in a fire $\left(40 \%\right.$ at $500{ }^{\circ} \mathrm{C}$ for high grade steel columns). This may be still adequate for a fire limit state as the fire design load is a fraction of ambient temperature design load. In contrast, in the case of fire exposed coldformed steel columns, the residual column capacity should not be reduced significantly as they need to be able to support the higher ambient temperature design loads. This appears to be satisfactory as both low and high grade steel columns retain $90 \%$ of their capacities if the exposed temperature is below $500{ }^{\circ} \mathrm{C}$.

\subsection{Conclusions}

This paper has described an investigation into the residual distortional buckling capacities of cold-formed steel columns after being exposed to elevated temperatures. Twenty seven tests were conducted on cold-formed steel lipped channel sections made of different grades and thicknesses (G300-1.00 mm, G500-1.15 mm and G550-0.95 mm) exposed to temperatures varying from $20-800{ }^{\circ} \mathrm{C}$. Suitable finite element models of tested columns were also developed and their results agreed well with test results when measured post-fire mechanical properties of the same cold-formed steels were used. A full description of the distortional buckling and ultimate strength behaviour of cold-formed steel compression members for ambient and exposed temperatures is presented in this paper including ultimate loads, failure modes and load-deformation curves. It was found that cold-formed steel columns were able to regain $90 \%$ of their original distortional buckling capacities if the exposed temperature was below $500{ }^{\circ} \mathrm{C}$. The reduction in ultimate capacity followed a similar trend to that of yield 
strength and hence post-fire mechanical properties alone can be used to predict the residual capacities conservatively. However, the reduction in ultimate capacities was less severe than that predicted by yield strength reduction factors for both low and high grade steel columns. Predictive equations proposed in this paper can be used to accurately predict the residual compression capacities of cold-formed steel columns after being exposed to fire events. A detailed comparison of ultimate capacity results with those predicted by the current ambient temperature design equations in AS/NZS 4600, AISI S100 and the direct strength method showed that these equations can also be used to predict the residual compression capacities reasonably well when appropriately reduced post-fire mechanical properties are used.

\section{Acknowledgements}

The authors would like to thank Australian Research Council for their financial support and the Queensland University of Technology for providing the necessary facilities and support to conduct this research project. They would also like to thank Daniel Marshall and Wade Gurtner for their assistance with the experimental study reported in this paper.

\section{References}

[1] Gunalan, S., Kolarkar, P.N. and Mahendran, M. (2013), Experimental study of load bearing cold-formed steel wall systems under fire conditions, Thin-Walled Structures, Vol. 65 , pp. 72-92.

[2] Gunalan, S. and Mahendran, M. (2013), Finite element modelling of load bearing coldformed steel wall systems under fire conditions, Engineering Structures, Vol. 56, pp. 10071027.

[3] Gunalan, S. and Mahendran, M. (2014), Review of current fire design rules for coldformed steel wall systems. Journal of Fire Sciences, Vol. 32, Issue 1, pp. 3-34.

[4] Gunalan, S. and Mahendran, M., (2014), Fire performance of cold-formed steel wall panels and prediction of their fire resistance rating, Fire Safety Journal, Vol. 64, pp. 61-80. 
[5] Gunalan, S. and Mahendran, M., (2013), Development of improved fire design rules for cold-formed steel wall systems, Journal of Constructional Steel Research, Vol. 88, pp. 339362.

[6] Ala-Outinen and Myllymaki, J. (1995) The local buckling of RHS members at elevated temperatures, VTT Research Notes 1672, Technical Research Centre of Finland, Espoo.

[7] Ranby, A. (1998) Structural fire design of thin-walled steel sections, Journal of Constructional Steel Research, Vol. 46, pp. 303-304.

[8] Kaitila, O. (2002) Imperfection sensitivity analysis of lipped channel columns at high temperatures, Journal of Constructional Steel Research, Vol. 58, pp. 333-351.

[9] Feng, M., Wang, Y. C. and. Davies J. M. (2003a) Structural behaviour of cold-formed thin-walled short steel channel columns at elevated temperatures, Part 1: Experiments, ThinWalled Structures, Vol. 41, pp. 543-570.

[10] Feng, M., Wang, Y.C. and Davies, J.M. (2003b) Structural behaviour of cold-formed thin-walled short steel channel columns at elevated temperatures. Part 2: Design calculations and numerical analysis, Thin-Walled Structures, Vol. 41, pp. 571-594.

[11] Chen, J. and Young B. (2007), Experimental investigation of cold-formed steel material at elevated temperatures, Thin-Walled Structures, Vol. 45, pp. 96-110.

[12] Ranawaka, T. and Mahendran, M. (2009), Distortional buckling tests of cold-formed steel compression members at elevated temperatures, Journal of Constructional Steel Research, Vol. 65, pp. 249-259.

[13] Ranawaka, T. and Mahendran, M. (2010), Numerical modelling of light gauge cold-formed steel compression members subjected to distortional buckling at elevated temperatures, ThinWalled Structures, Vol. 48, pp. 334-344. 
[14] Gunalan, S., Bandula Heva, Y. and Mahendran, M. (2014), Local buckling studies of cold-formed steel compression members at elevated temperatures, Journal of Constructional Steel Research, Submitted in November 2013.

[15] Bandula Heva, Y. and Mahendran, M. (2012), Flexural-torsional buckling tests of cold-formed steel compression members at elevated temperatures. Steel and Composite Structures, Vol. 14, pp. 205-227.

[16] Gunalan, S., Bandula Heva, Y. and Mahendran, M. (2014), Flexural-torsional buckling behaviour and design of cold-formed steel compression members at elevated temperatures, Engineering Structures, In Press, http://dx.doi.org/10.1016/j.engstruct.2014.07.036

[17] Gunalan, S. and Mahendran, M. (2013), Improved design rules for fixed ended coldformed steel columns subject to flexural-torsional buckling. Thin-Walled Structures, Vol. 73, pp. 1-17.

[18] Dolamune Kankanamge, N. and Mahendran, M. (2011), Mechanical properties of coldformed steels at elevated temperatures, Thin-Walled Structures, Vol. 49, pp. 26-44.

[19] Dill, F.H. (1960), Structural steel after a fire, Proceedings of AISC National Engineering Conference, pp. 78-80.

[20] Tide, R.H.R. (1998), Integrity of structural steel after exposure to fire, Engineering Journal, pp. 26.

[21] Chan, D. (2009), Fire damage assessment of structural steel in a school, The Structural Engineer, 87(19), pp.18-20.

[22] Kirby, B.R., Lapwood, D.G. and Thomson, G. (1993), The reinstatement of fire damaged steel and iron framed structures, Technical Report, British Steel Swinden Laboratories, London, UK. 
[23] British Standard Institution (BSI) (1990), Structural use of steel work in building. Part 8: Code of practice for fire resistant design, BS 5950-5, London, UK.

[24] European Committee for Standardization (ECS) (2005), Eurocode 3: Design of steel structures. Part 1.2: General rules - Structural fire design, Brussels.

[25] Qiang, X., Bijlaard, F.S.K. and Kolstein, H. (2012), Post-fire mechanical properties of high strength structural steels S460 and S690, Engineering Structures, Vol. 35, pp. 1-10.

[26] Outinen, J. and Makelainen, P. (2004), Mechanical properties of structural steel at elevated temperatures and after cooling down, Fire and Materials, Vol. 28, pp. 237-251.

[27] Gunalan, S. and Mahendran, M. (2014), Experimental investigation of post-fire mechanical properties of cold-formed steels, Thin-Walled Structures, Vol. 84, pp. 241-254.

[28] Standards Australia (SA) (2005), Cold-formed steel structures, AS/NZS 4600, Sydney, Australia.

[29] American Iron and Steel Institute (AISI) (2007), Specifications for the cold-formed steel structural members, Cold-formed Steel Design Manual, AISI S100, Washington, USA.

[30] Schafer, B.W. (2008), Review: The direct strength method of cold-formed steel member design, Journal of Constructional Steel Research, Vol. 64, pp. 766-778

[31] Lau, S. C. W. and Hancock, G. J. (1987) Distortional buckling formulas for channel column, Journal of Structural Engineering, Vol. 113, pp. 1063-1078.

[32] Kwon, Y.B., and Hancock, G.J. (1992) Strength tests of cold-formed channel sections undergoing local and distortional buckling, Journal of Structural Engineering, pp. 1786-1803. 
Table 1: Post-fire elastic modulus and reduction factors

\begin{tabular}{|c|c|c|c|c|c|c|}
\hline \multirow{2}{*}{$\mathrm{T}\left({ }^{\circ} \mathrm{C}\right)$} & \multicolumn{3}{|c|}{ Elastic modulus (MPa) } & \multicolumn{3}{c|}{ Reduction factor } \\
\cline { 2 - 7 } & G300-1.00 & G500-1.15 & G550-0.95 & G300-1.00 & G500-1.15 & G550-0.95 \\
\hline 20 & 209053 & 227096 & 231575 & 1.000 & 1.000 & 1.000 \\
\hline 300 & 210390 & 225867 & 231660 & 1.006 & 0.995 & 1.000 \\
\hline 400 & 212014 & 225131 & 230013 & 1.014 & 0.991 & 0.993 \\
\hline 500 & 209532 & 224223 & 226776 & 1.002 & 0.987 & 0.979 \\
\hline 550 & 207123 & 219095 & 210002 & 0.991 & 0.965 & 0.907 \\
\hline 600 & 210697 & 216504 & 209715 & 1.008 & 0.953 & 0.906 \\
\hline 650 & 207576 & 208246 & 210482 & 0.993 & 0.917 & 0.909 \\
\hline 700 & 207103 & 207012 & 208114 & 0.991 & 0.912 & 0.899 \\
\hline 750 & 205712 & 203279 & 205746 & 0.984 & 0.895 & 0.888 \\
\hline 800 & 201516 & 203440 & 197724 & 0.964 & 0.896 & 0.854 \\
\hline
\end{tabular}

Table 2: Post-fire yield strengths and reduction factors

\begin{tabular}{|c|c|c|c|c|c|c|}
\hline \multirow{2}{*}{$\mathrm{T}\left({ }^{\circ} \mathrm{C}\right)$} & \multicolumn{3}{|c|}{ Yield strength (MPa) } & \multicolumn{3}{c|}{ Reduction factor } \\
\cline { 2 - 7 } & G300-1.00 & G500-1.15 & G550-0.95 & G300-1.00 & G500-1.15 & G550-0.95 \\
\hline 20 & 351.5 & 663.9 & 664.4 & 1.000 & 1.000 & 1.000 \\
\hline 300 & 324.2 & 657.3 & 671.1 & 0.922 & 0.990 & 1.010 \\
\hline 400 & 323.6 & 651.3 & 653.9 & 0.921 & 0.981 & 0.984 \\
\hline 500 & 306.5 & 608.6 & 553.3 & 0.872 & 0.917 & 0.833 \\
\hline 550 & 300.5 & 409.1 & 309.8 & 0.855 & 0.616 & 0.466 \\
\hline 600 & 308.8 & 286.4 & 300.3 & 0.879 & 0.431 & 0.452 \\
\hline 650 & 297.1 & 232.8 & 283.2 & 0.845 & 0.351 & 0.426 \\
\hline 700 & 254.2 & 261.7 & 272 & 0.723 & 0.394 & 0.409 \\
\hline 750 & 238.9 & 246.8 & 260.6 & 0.680 & 0.372 & 0.392 \\
\hline 800 & 204 & 262.4 & 241.7 & 0.579 & 0.395 & 0.364 \\
\hline
\end{tabular}


Table 3: Measured dimensions of test specimens

\begin{tabular}{|c|c|c|c|c|c|c|}
\hline Test & Grade & $\begin{array}{c}\text { Temp. } \\
\left({ }^{\circ} \mathrm{C}\right)\end{array}$ & $\begin{array}{c}\text { Web } \\
(\mathrm{mm})\end{array}$ & $\begin{array}{c}\text { Flange } \\
(\mathrm{mm})\end{array}$ & $\begin{array}{c}\text { Lip } \\
(\mathrm{mm})\end{array}$ & $\begin{array}{c}\text { Thickness } \\
(\mathrm{mm})\end{array}$ \\
\hline 1 & G300 & 20 & 40.2 & 40.0 & 5.0 & 1.00 \\
\hline 2 & G300 & 400 & 40.2 & 39.9 & 5.0 & 1.01 \\
\hline 3 & G300 & 500 & 40.3 & 40.2 & 5.2 & 1.01 \\
\hline 4 & G300 & 550 & 40.3 & 40.1 & 5.0 & 1.01 \\
\hline 5 & G300 & 600 & 40.4 & 40.0 & 4.8 & 1.00 \\
\hline 6 & G300 & 650 & 40.5 & 40.0 & 5.0 & 1.00 \\
\hline 7 & G300 & 700 & 40.4 & 40.0 & 5.3 & 1.01 \\
\hline 8 & G300 & 750 & 40.4 & 39.9 & 5.0 & 1.01 \\
\hline 9 & G300 & 800 & 40.2 & 40.2 & 5.2 & 1.00 \\
\hline 10 & G500 & 20 & 39.5 & 39.6 & 4.6 & 1.14 \\
\hline 11 & G500 & 400 & 39.6 & 39.6 & 4.8 & 1.14 \\
\hline 12 & G500 & 500 & 39.6 & 39.6 & 4.7 & 1.14 \\
\hline 13 & G500 & 550 & 39.8 & 40.0 & 5.2 & 1.14 \\
\hline 14 & G500 & 600 & 39.7 & 40.0 & 5.0 & 1.16 \\
\hline 15 & G500 & 650 & 40.4 & 40.5 & 5.4 & 1.16 \\
\hline 16 & G500 & 700 & 40.4 & 40.5 & 5.4 & 1.16 \\
\hline 17 & G500 & 750 & 39.6 & 40.0 & 5.3 & 1.15 \\
\hline 18 & G500 & 800 & 39.8 & 39.9 & 5.0 & 1.14 \\
\hline 19 & G550 & 20 & 40.3 & 39.7 & 4.3 & 0.96 \\
\hline 20 & G550 & 400 & 40.3 & 39.7 & 4.3 & 0.96 \\
\hline 21 & G550 & 500 & 39.6 & 39.5 & 4.3 & 0.94 \\
\hline 22 & G550 & 550 & 40.0 & 39.8 & 4.8 & 0.95 \\
\hline 23 & G550 & 600 & 40.2 & 39.7 & 4.8 & 0.96 \\
\hline 24 & G550 & 650 & 41.8 & 39.7 & 4.7 & 0.95 \\
\hline 25 & G550 & 700 & 40.5 & 40.4 & 5.1 & 0.96 \\
\hline 26 & G550 & 750 & 39.0 & 40.0 & 5.2 & 0.96 \\
\hline 27 & G550 & 800 & 40.7 & 40.2 & 4.9 & 0.96 \\
\hline
\end{tabular}


Table 4: Comparison of ultimate loads from tests, FEA and design standards

\begin{tabular}{|c|c|c|c|c|c|c|c|c|c|c|}
\hline \multirow[b]{2}{*}{ Test } & \multirow{2}{*}{$\begin{array}{l}\text { EBL } \\
(\mathrm{kN}) \\
\text { FEA }\end{array}$} & \multicolumn{4}{|c|}{$\mathrm{P}_{\mathrm{ult}}(\mathrm{kN})$} & \multicolumn{5}{|c|}{$\mathrm{P}_{\text {ult }}$ ratios } \\
\hline & & Test & FEA & $\begin{array}{c}\mathrm{AS} / \\
\mathrm{NZS} \\
4600\end{array}$ & DSM & $\begin{array}{l}\text { Test/ } \\
\text { FEA }\end{array}$ & $\begin{array}{c}\text { Test/ } \\
\text { AS/NZS } \\
4600\end{array}$ & $\begin{array}{l}\text { Test/ } \\
\text { DSM }\end{array}$ & $\begin{array}{c}\text { FEA/ } \\
\text { AS/NZS } \\
4600\end{array}$ & $\begin{array}{l}\text { FEA/ } \\
\text { DSM }\end{array}$ \\
\hline 1 & 40.7 & 30.8 & 33.2 & 32.2 & 32.1 & 0.93 & 0.95 & 0.96 & 1.03 & 1.03 \\
\hline 2 & 42.2 & 35.3 & 32.5 & 31.1 & 31.2 & 1.09 & 1.13 & 1.13 & 1.04 & 1.04 \\
\hline 3 & 43.3 & 36.2 & 32.1 & 30.4 & 30.6 & 1.13 & 1.19 & 1.18 & 1.06 & 1.05 \\
\hline 4 & 41.0 & 31.8 & 30.8 & 29.3 & 29.5 & 1.03 & 1.08 & 1.08 & 1.05 & 1.04 \\
\hline 5 & 39.2 & 31.6 & 29.0 & 29.3 & 29.3 & 1.09 & 1.08 & 1.08 & 0.99 & 0.99 \\
\hline 6 & 40.4 & 28.6 & 28.4 & 28.8 & 29.0 & 1.01 & 0.99 & 0.99 & 0.99 & 0.98 \\
\hline 7 & 44.6 & 29.5 & 26.1 & 26.6 & 27.4 & 1.13 & 1.11 & 1.08 & 0.98 & 0.95 \\
\hline 8 & 41.0 & 22.6 & 24.5 & 24.8 & 25.5 & 0.92 & 0.91 & 0.88 & 0.99 & 0.96 \\
\hline 9 & 40.7 & 24.0 & 23.2 & 21.7 & 22.8 & 1.04 & 1.10 & 1.05 & 1.07 & 1.02 \\
\hline 10 & 53.6 & 54.2 & 60.3 & 52.7 & 54.9 & 0.90 & 1.03 & 0.99 & 1.14 & 1.10 \\
\hline 11 & 55.4 & 48.9 & 54.7 & 53.8 & 55.3 & 0.89 & 0.91 & 0.88 & 1.02 & 0.99 \\
\hline 12 & 54.0 & 48.4 & 52.7 & 51.7 & 52.7 & 0.92 & 0.94 & 0.92 & 1.02 & 1.00 \\
\hline 13 & 58.2 & 44.2 & 43.5 & 43.8 & 43.8 & 1.02 & 1.01 & 1.01 & 0.99 & 0.99 \\
\hline 14 & 57.3 & 38.8 & 35.8 & 34.0 & 35.1 & 1.08 & 1.14 & 1.11 & 1.05 & 1.02 \\
\hline 15 & 60.6 & 35.9 & 31.3 & 29.6 & 31.4 & 1.15 & 1.21 & 1.14 & 1.06 & 1.00 \\
\hline 16 & 60.2 & 37.9 & 34.7 & 32.5 & 34.0 & 1.09 & 1.16 & 1.11 & 1.07 & 1.02 \\
\hline 17 & 56.0 & 31.9 & 31.8 & 30.0 & 31.4 & 1.00 & 1.06 & 1.01 & 1.06 & 1.01 \\
\hline 18 & 51.9 & 34.9 & 32.2 & 30.7 & 31.7 & 1.08 & 1.14 & 1.10 & 1.05 & 1.02 \\
\hline 19 & 36.2 & 38.1 & 42.0 & 38.4 & 41.8 & 0.91 & 0.99 & 0.91 & 1.09 & 1.00 \\
\hline 20 & 35.0 & 41.5 & 41.2 & 37.6 & 40.8 & 1.01 & 1.11 & 1.02 & 1.10 & 1.01 \\
\hline 21 & 33.1 & 33.2 & 35.8 & 33.1 & 35.9 & 0.93 & 1.00 & 0.93 & 1.08 & 1.00 \\
\hline 22 & 36.7 & 25.7 & 28.4 & 27.6 & 27.6 & 0.91 & 0.93 & 0.93 & 1.03 & 1.03 \\
\hline 23 & 35.2 & 29.0 & 26.8 & 26.9 & 26.8 & 1.08 & 1.08 & 1.08 & 1.00 & 1.00 \\
\hline 24 & 34.4 & 25.9 & 26.6 & 25.6 & 25.6 & 0.97 & 1.01 & 1.01 & 1.04 & 1.04 \\
\hline 25 & - & - & - & - & - & - & - & - & - & - \\
\hline 26 & 38.4 & 29.2 & 26.7 & 25.1 & 25.5 & 1.09 & 1.17 & 1.14 & 1.07 & 1.05 \\
\hline 27 & 34.2 & 24.9 & 22.8 & 23.1 & 23.4 & 1.09 & 1.08 & 1.07 & 0.99 & 0.97 \\
\hline \multicolumn{6}{|c|}{ Mean } & 1.019 & 1.068 & 1.041 & 1.040 & 1.012 \\
\hline \multicolumn{6}{|c|}{$\mathrm{COV}$} & 0.082 & 0.093 & 0.096 & 0.039 & 0.031 \\
\hline \multicolumn{6}{|c|}{$\varphi$} & - & 0.938 & 0.911 & 0.951 & 0.928 \\
\hline
\end{tabular}




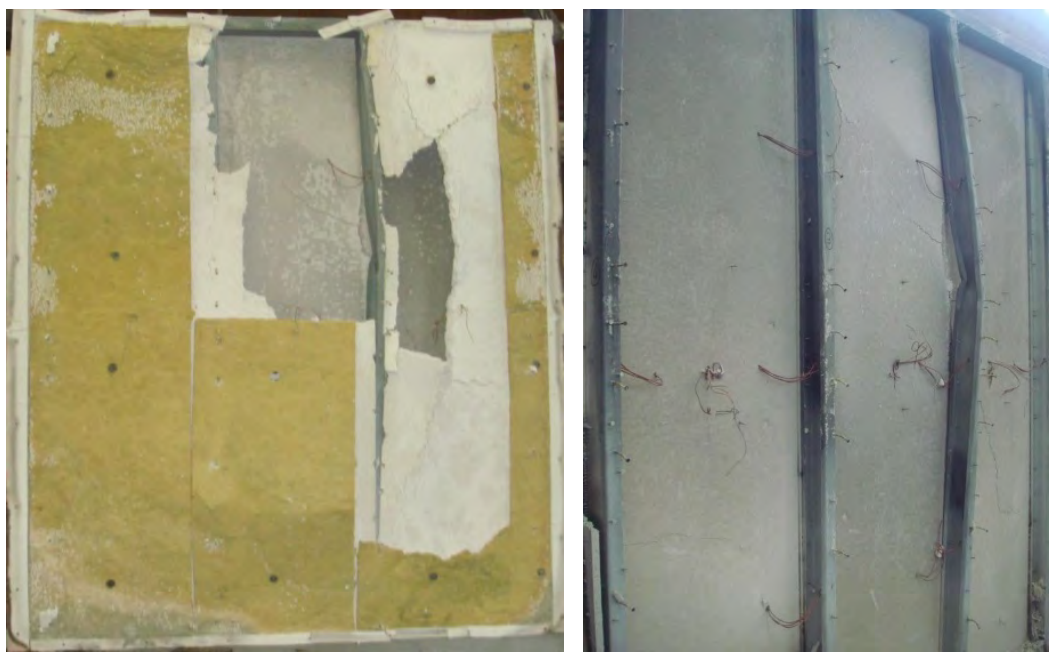

(a) LSF wall after fire

(b) Steel frame after fire

Figure 1: Fire damaged structure 


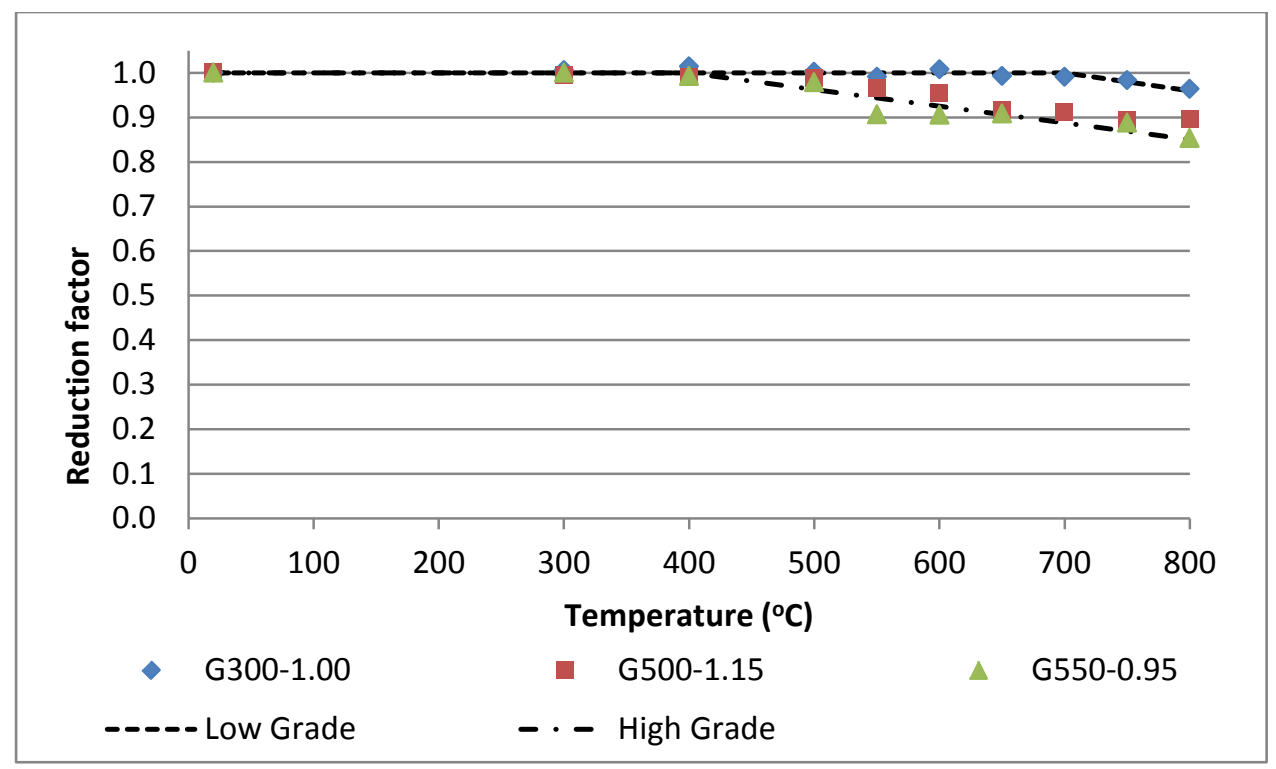

(a) Elastic modulus

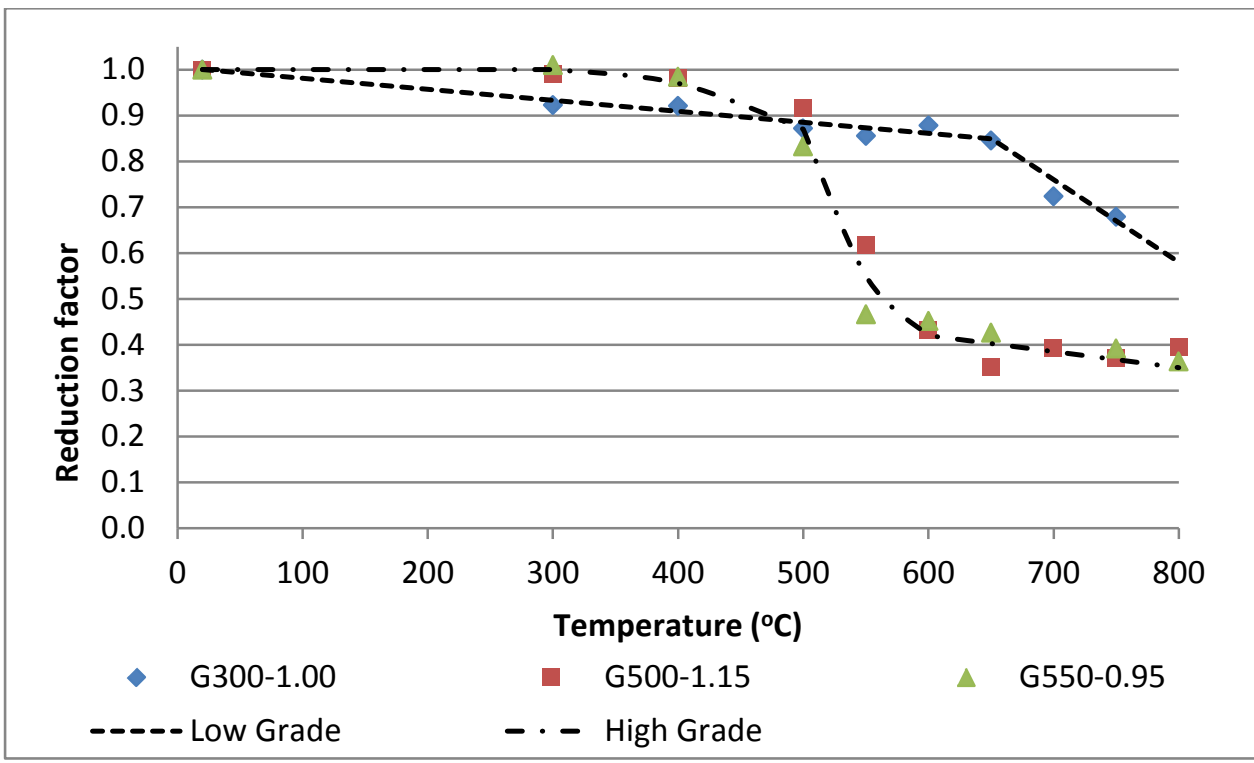

(b) Yield strength

Figure 2: Reduction factors versus exposed temperatures 


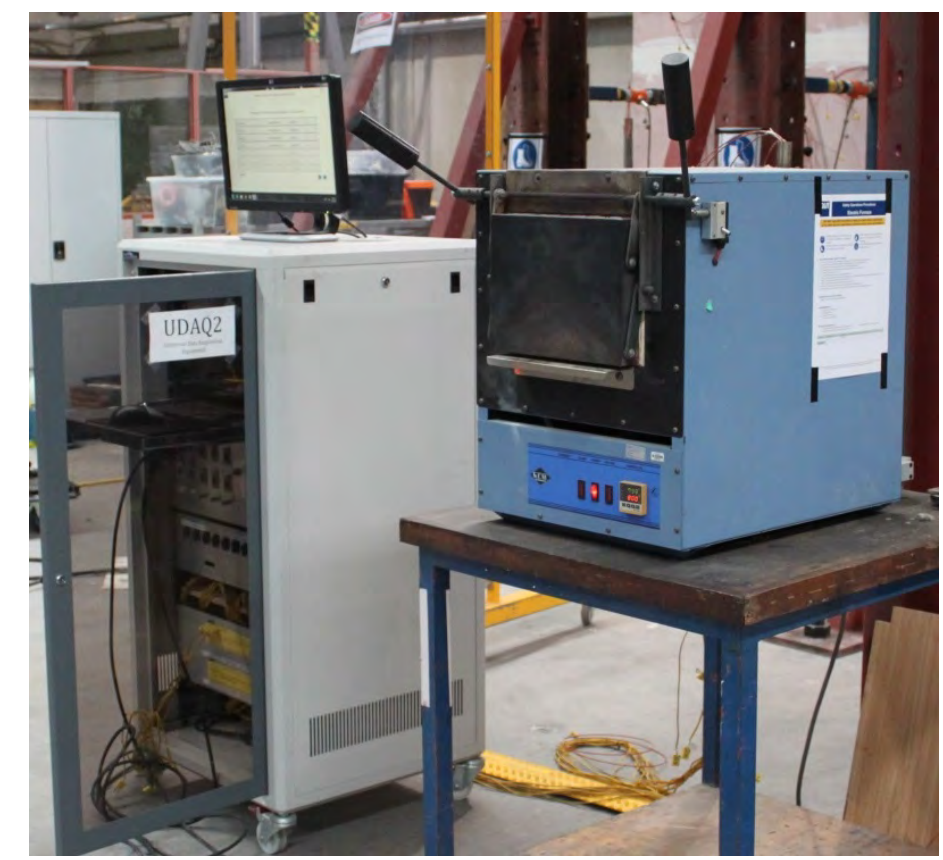

Figure 3: Electric furnace used for heating the test specimens
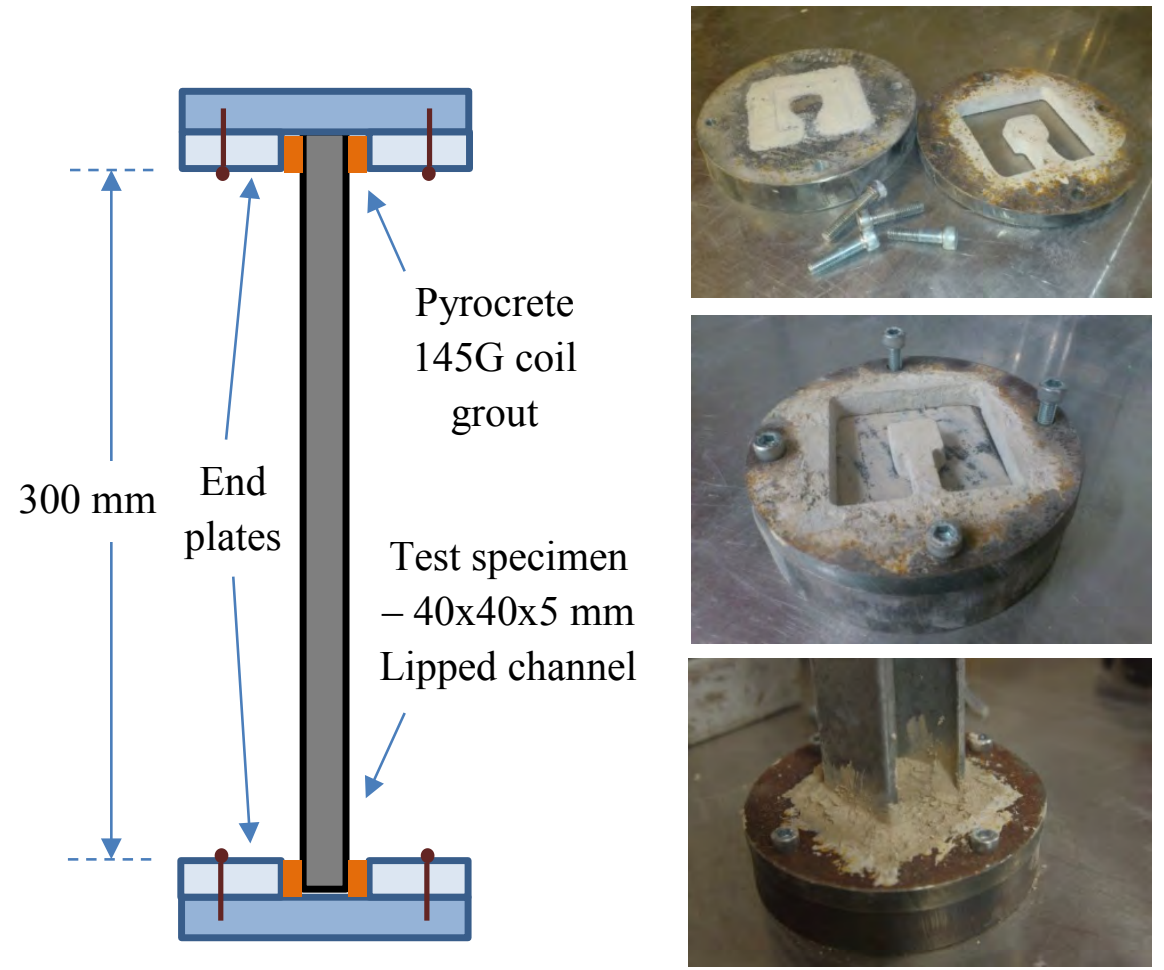

Figure 4: End support conditions of test specimens 

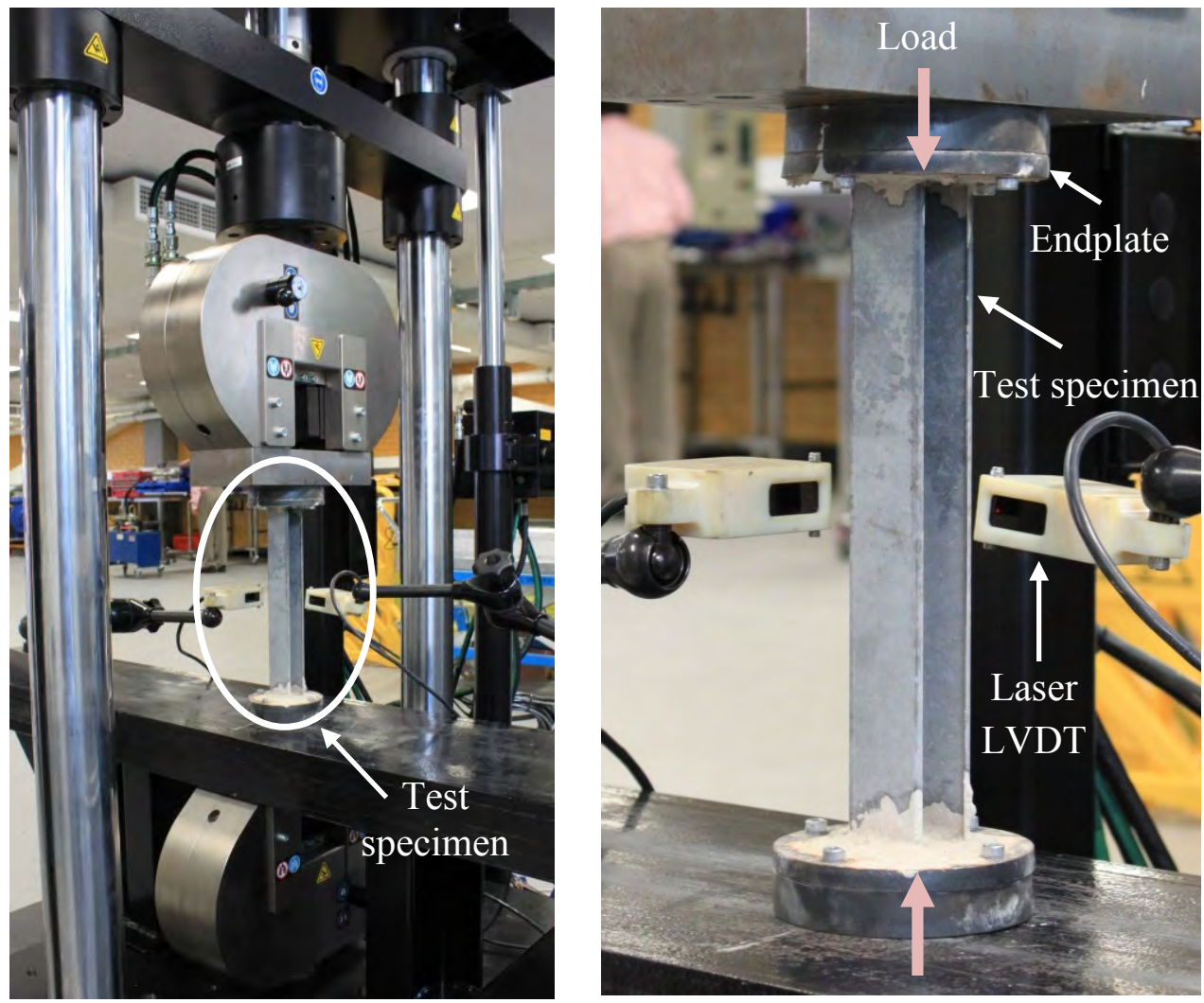

Figure 5: Test set-up for compression tests 


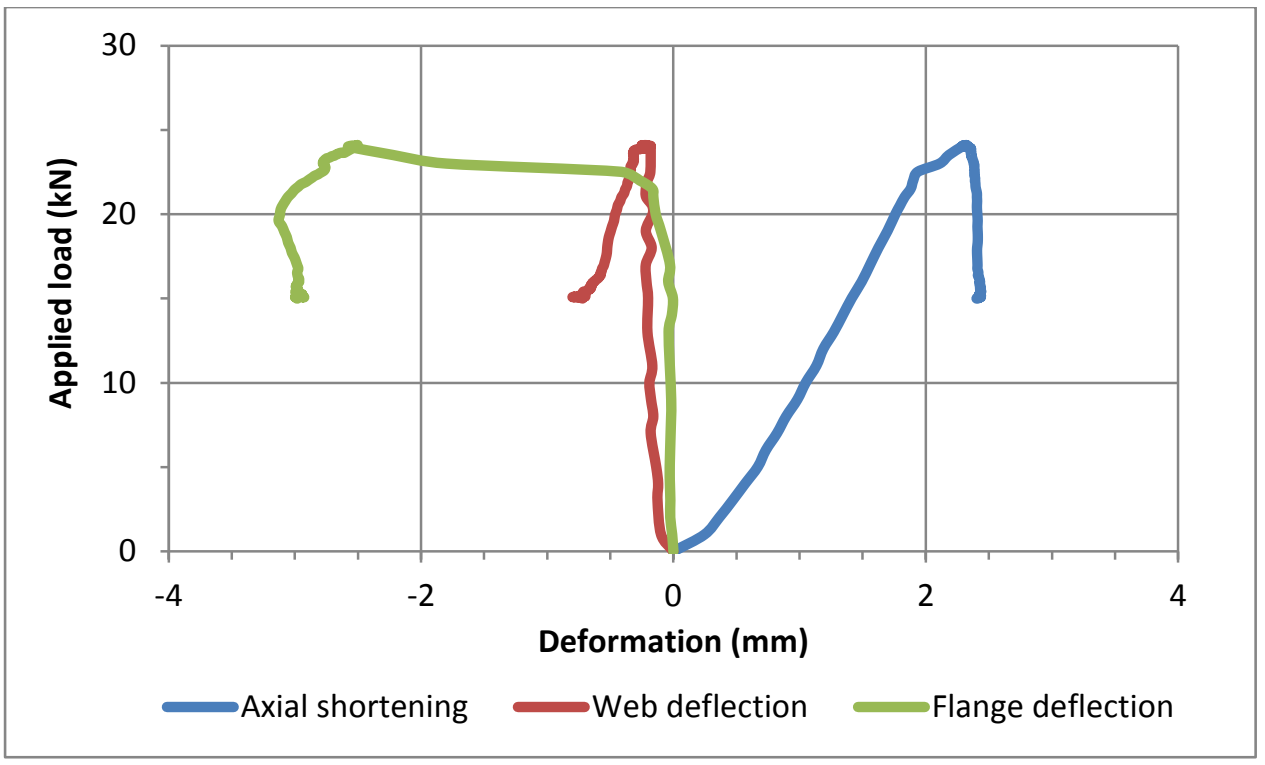

(a) G300-1.00 steel section

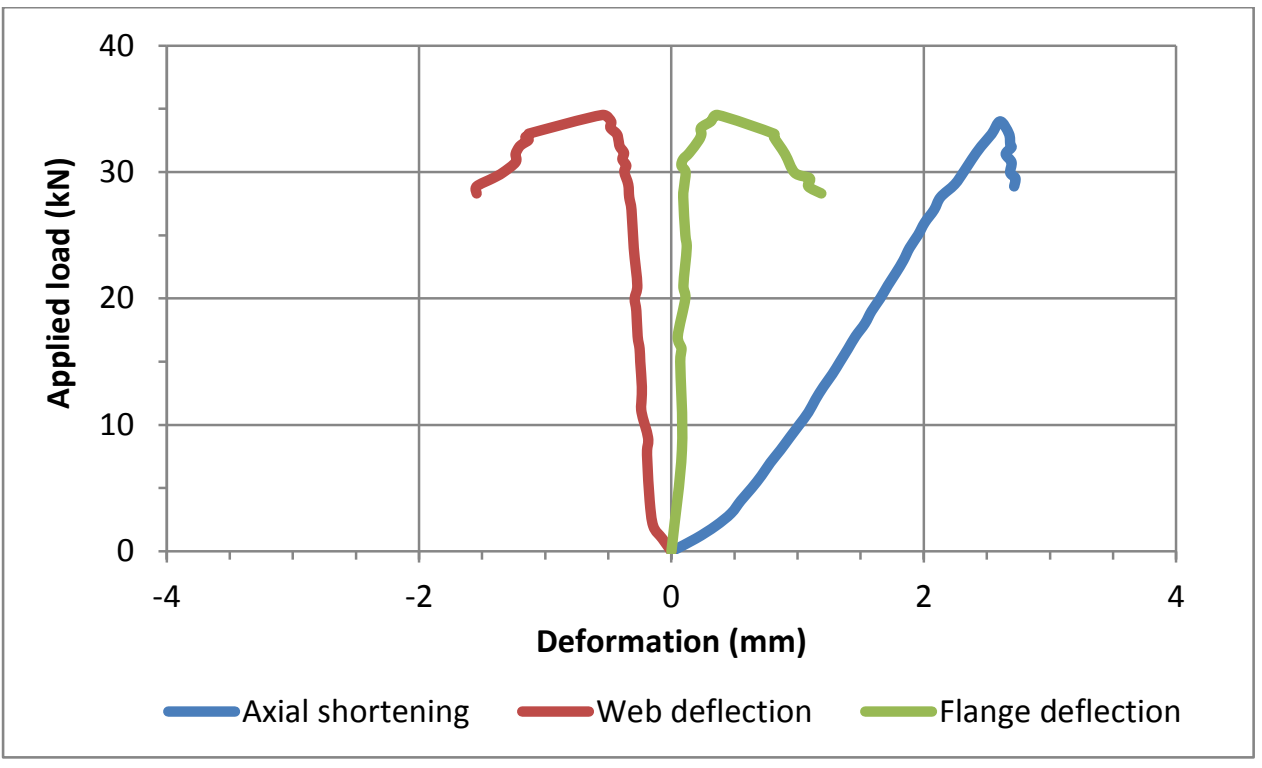

(b) G500-1.15 steel section

Figure 6: Typical load-deflection curves at $800{ }^{\circ} \mathrm{C}$ 


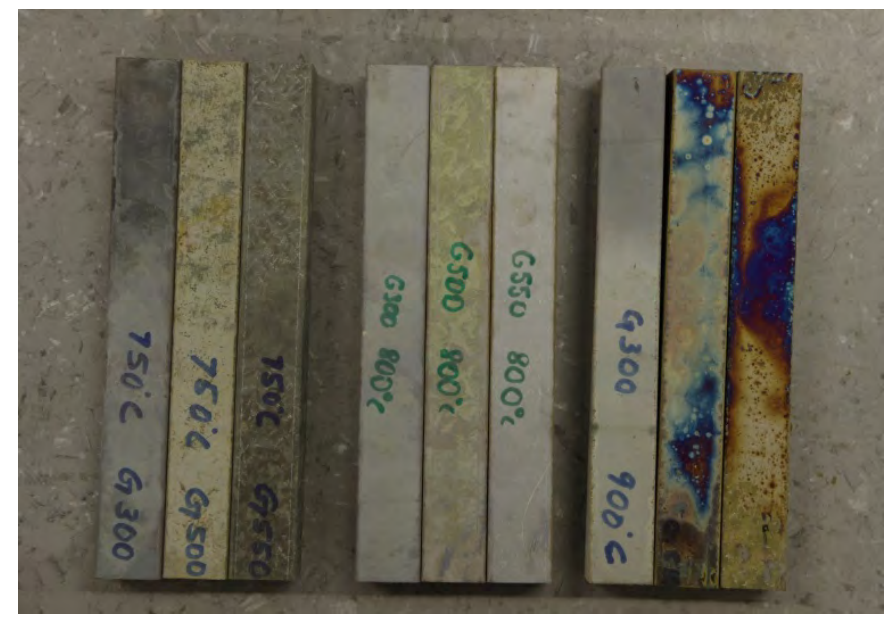

Figure 7: Test specimens after being exposed to temperatures above $700{ }^{\circ} \mathrm{C}$

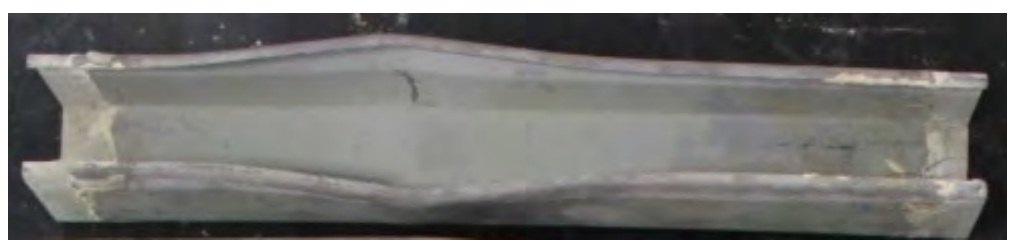

(a) G300-1.00 specimen

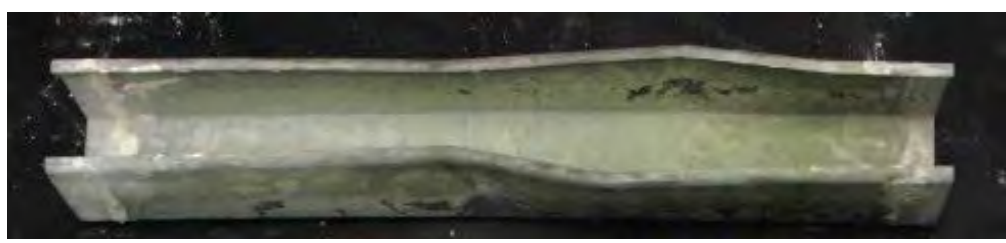

(b) G500-1.15 specimen

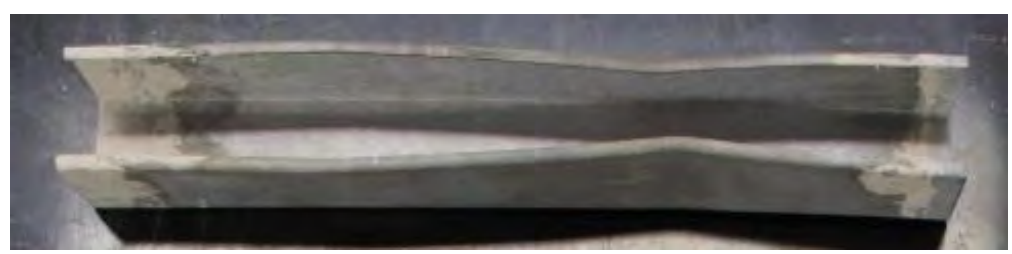

(c) G550-0.95 specimen

Figure 8: Distortional buckling failure modes for an exposed temperature of $800{ }^{\circ} \mathrm{C}$ 


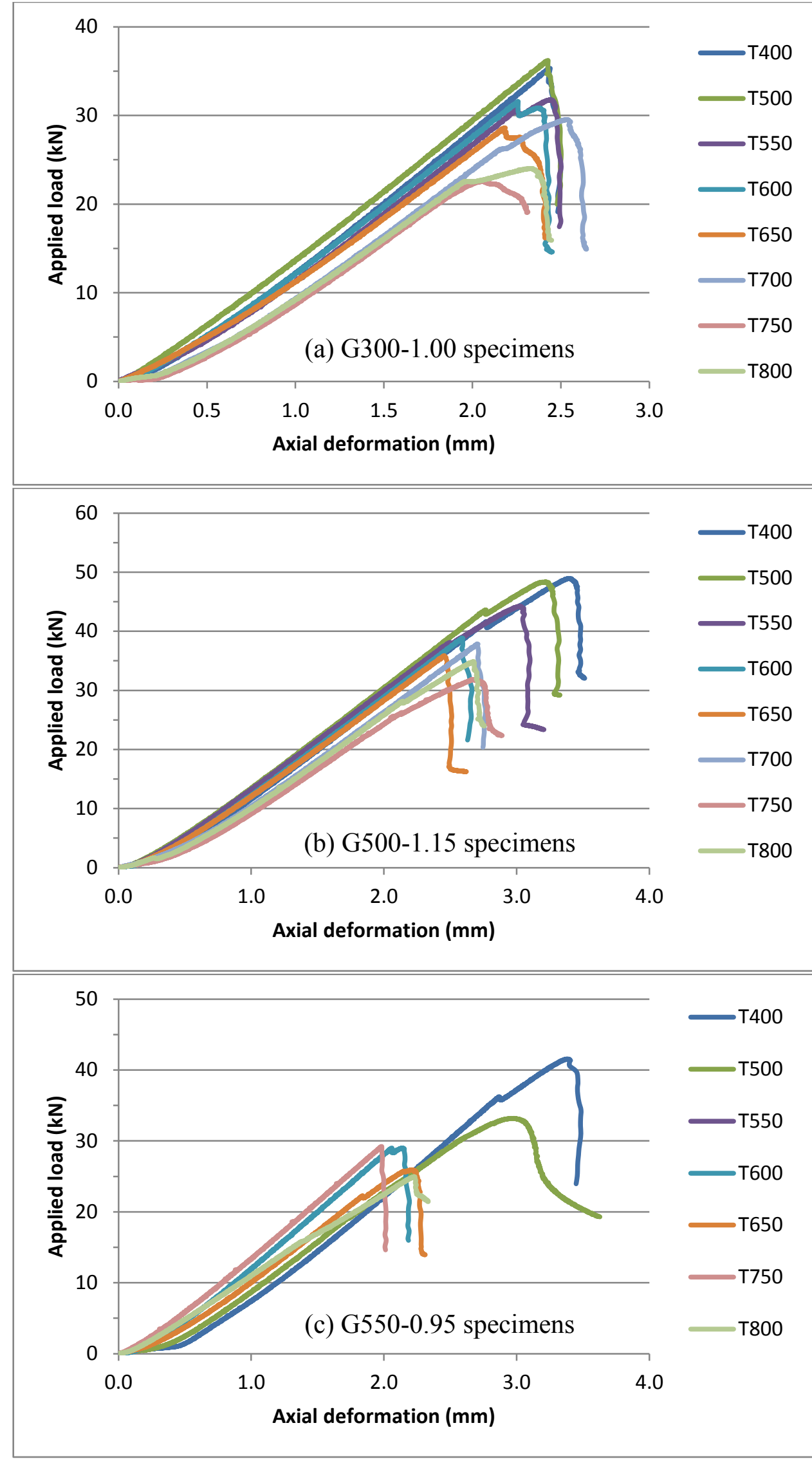

Figure 9: Comparison of load-deflection curves for different exposed temperatures 


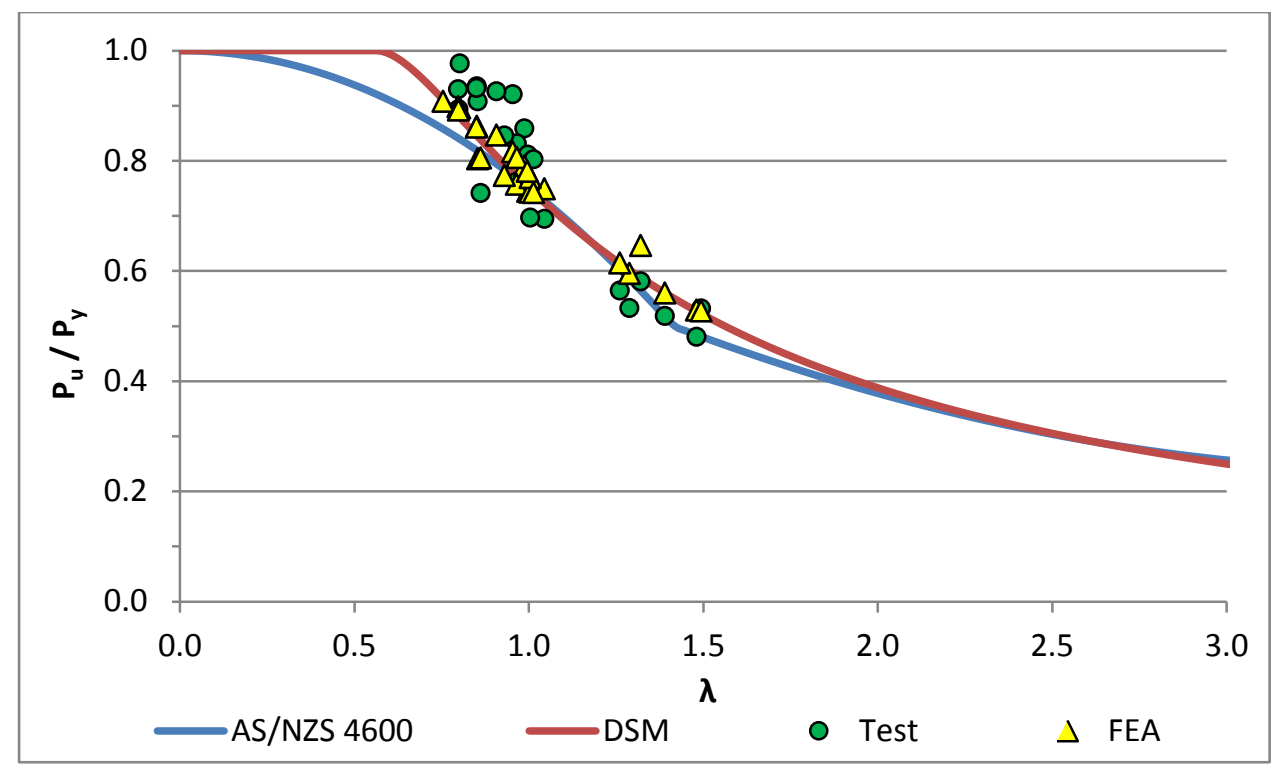

Figure 10: Comparison of test and FEA results with code predictions 


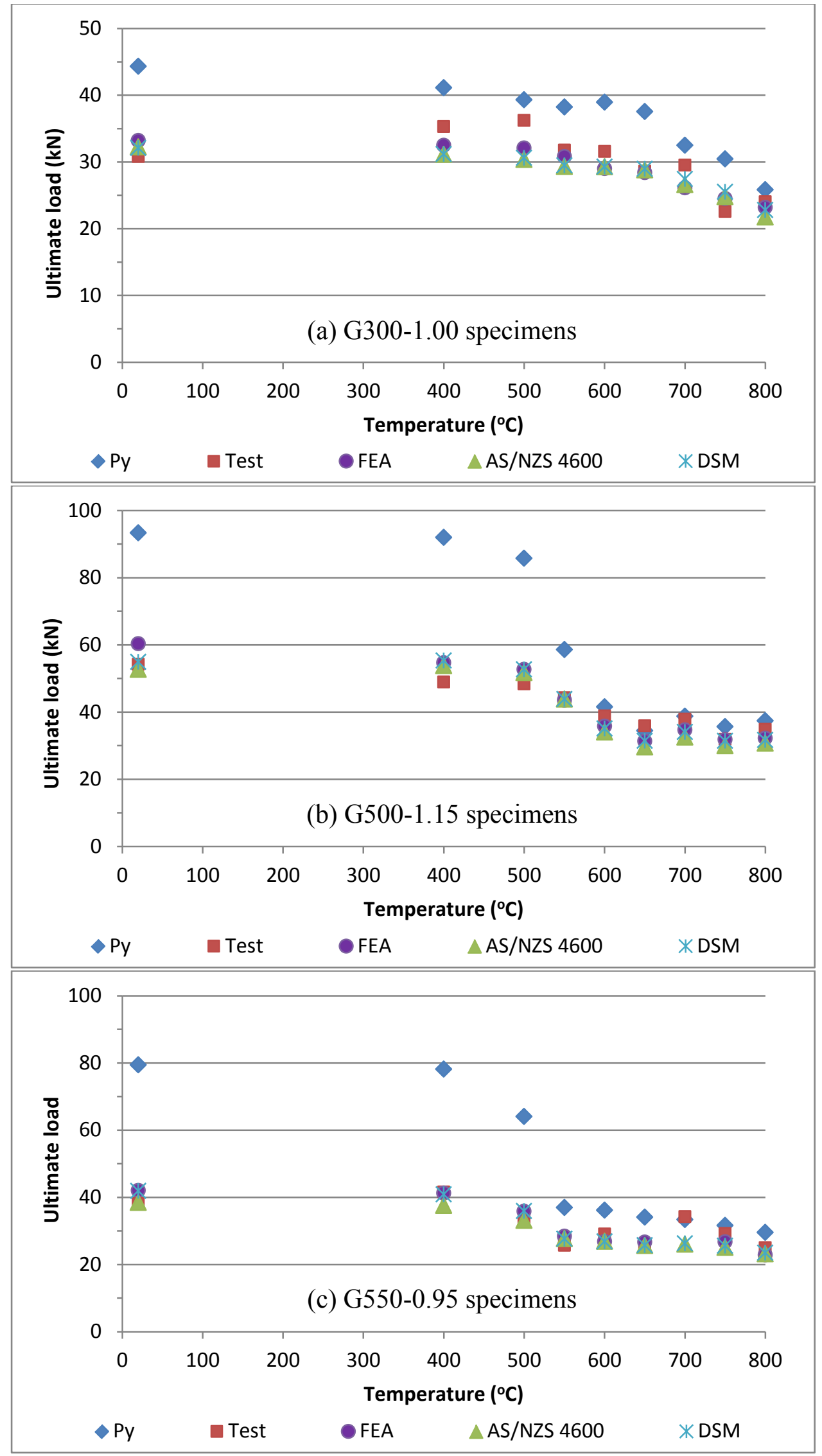

Figure 11: Ultimate load versus exposed temperatures 


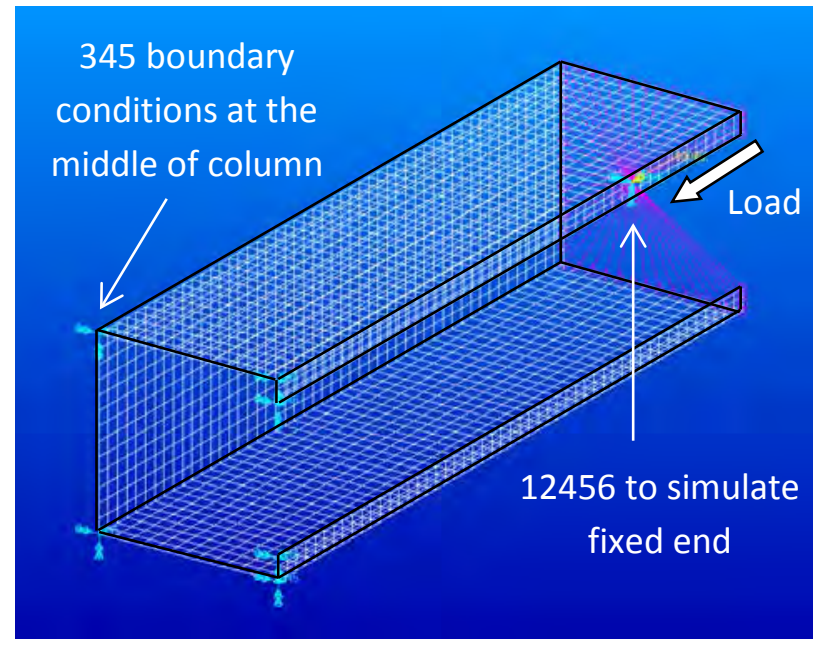

Load and end boundary conditions applied to the centroid of the section through MPC

Figure 12: Loading and boundary conditions used in FEA

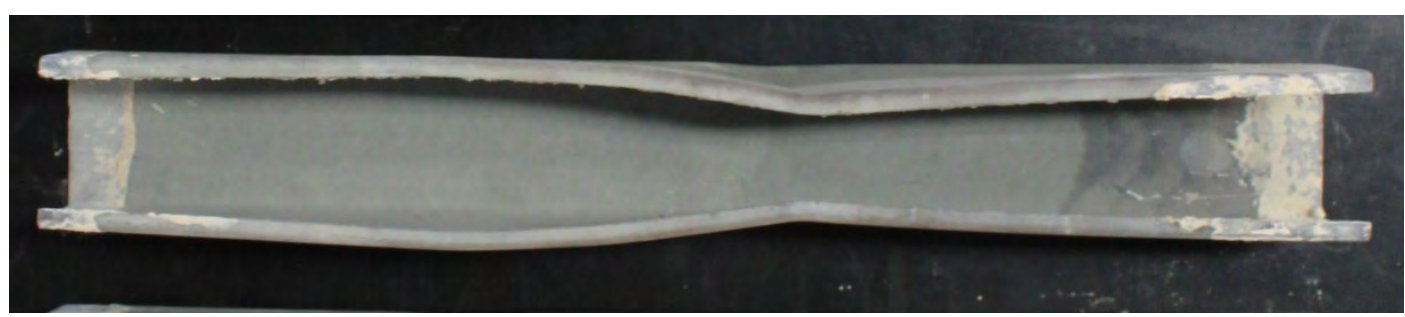

(a) Test

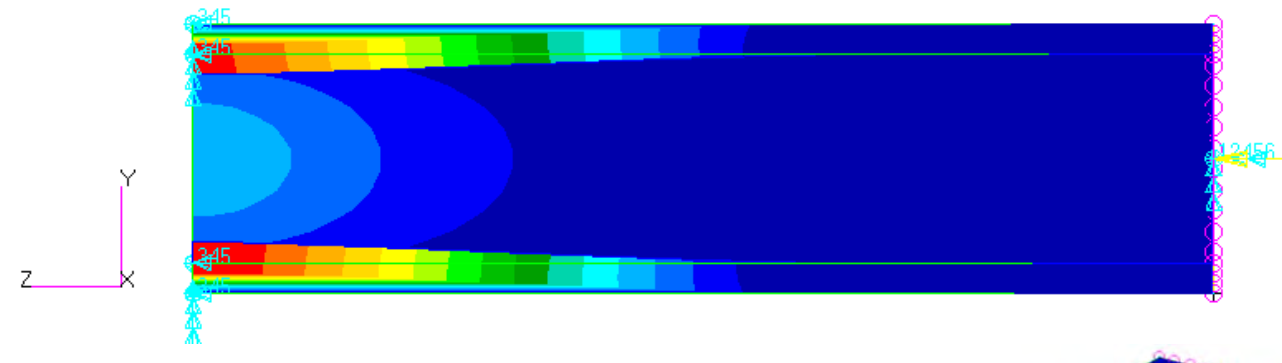

(b) FEA (Half-length model)
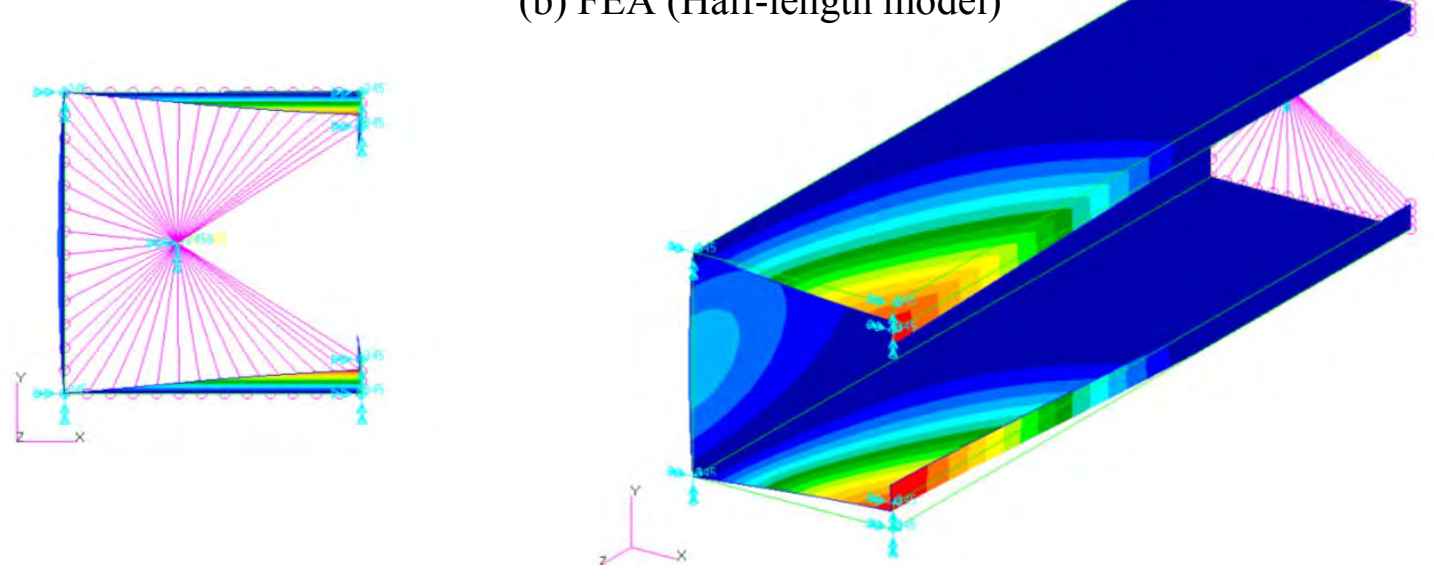

Figure 13: Distortional failure modes in test and FEA for G300-1.00 $\mathrm{mm}$ column for an exposed temperature of $650^{\circ} \mathrm{C}$ 


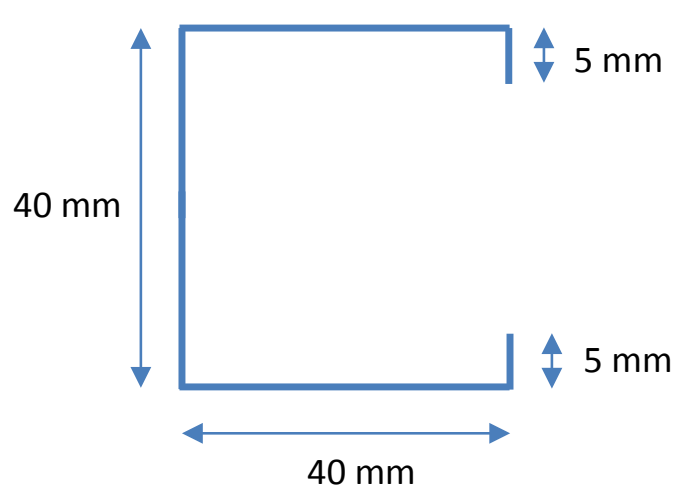

(a) Section 1

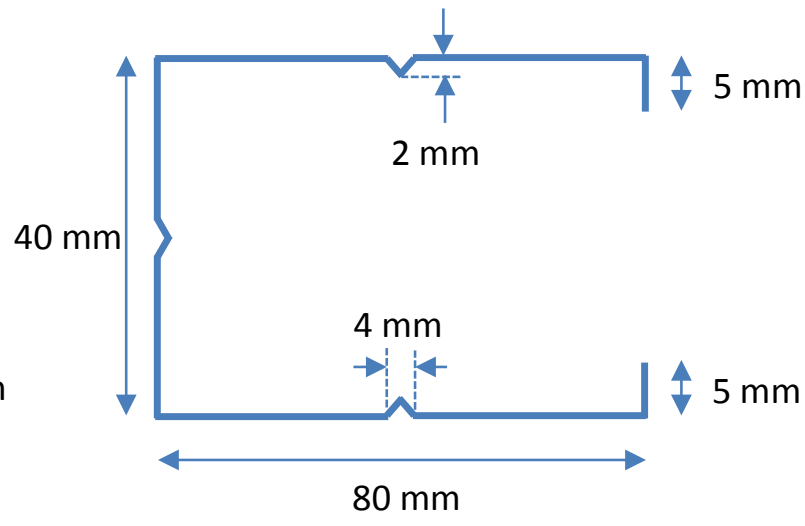

(b) Section 2

Figure 14: Sections considered in the parametric study

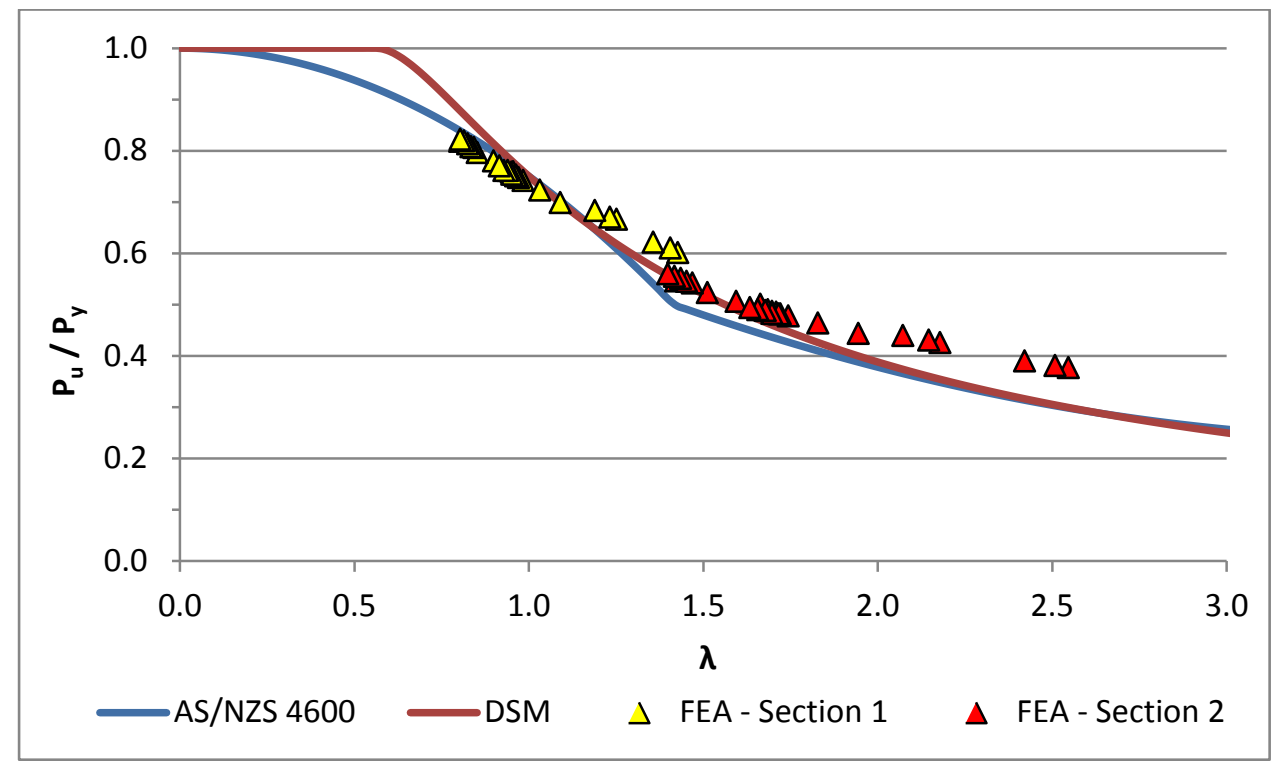

Figure 15: Comparison of parametric FEA results with code predictions 


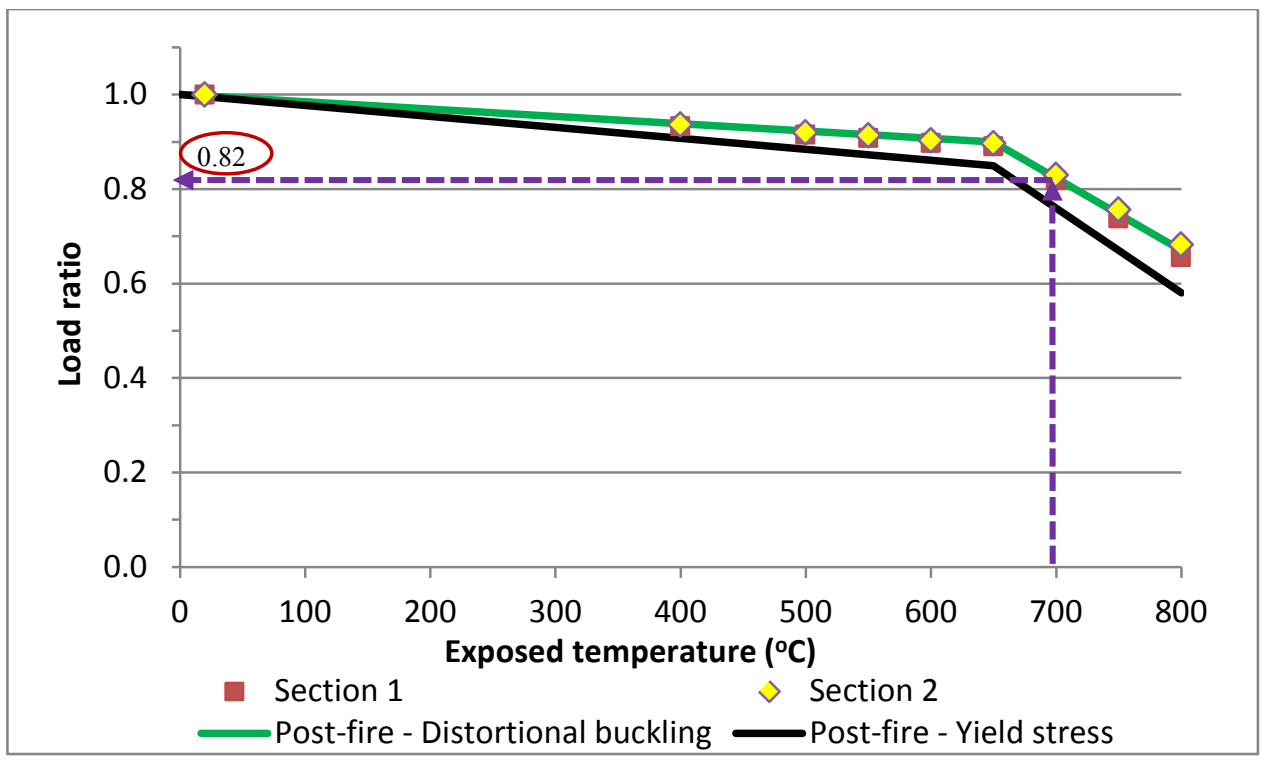

(a) Low grade steel columns

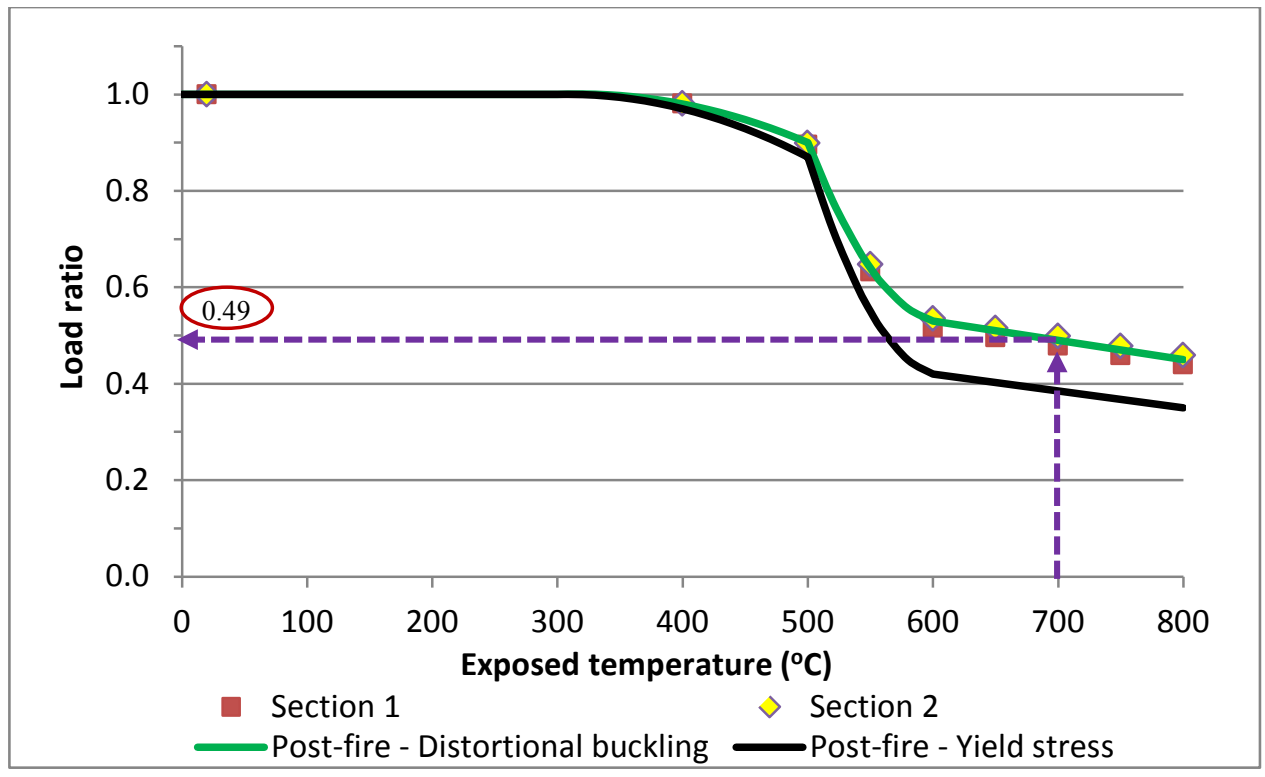

(b) High grade steel columns

Figure 16: Simplified method to find the residual capacity 


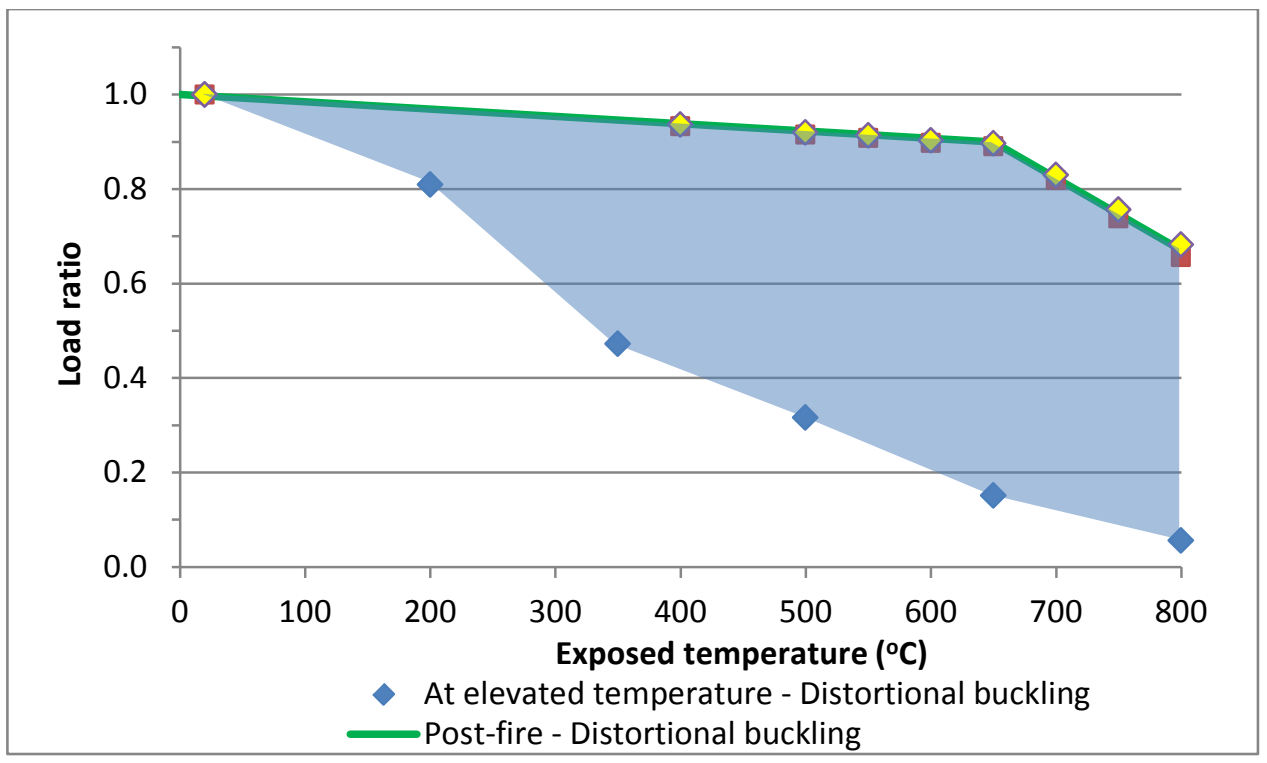

(a) Low grade steel columns

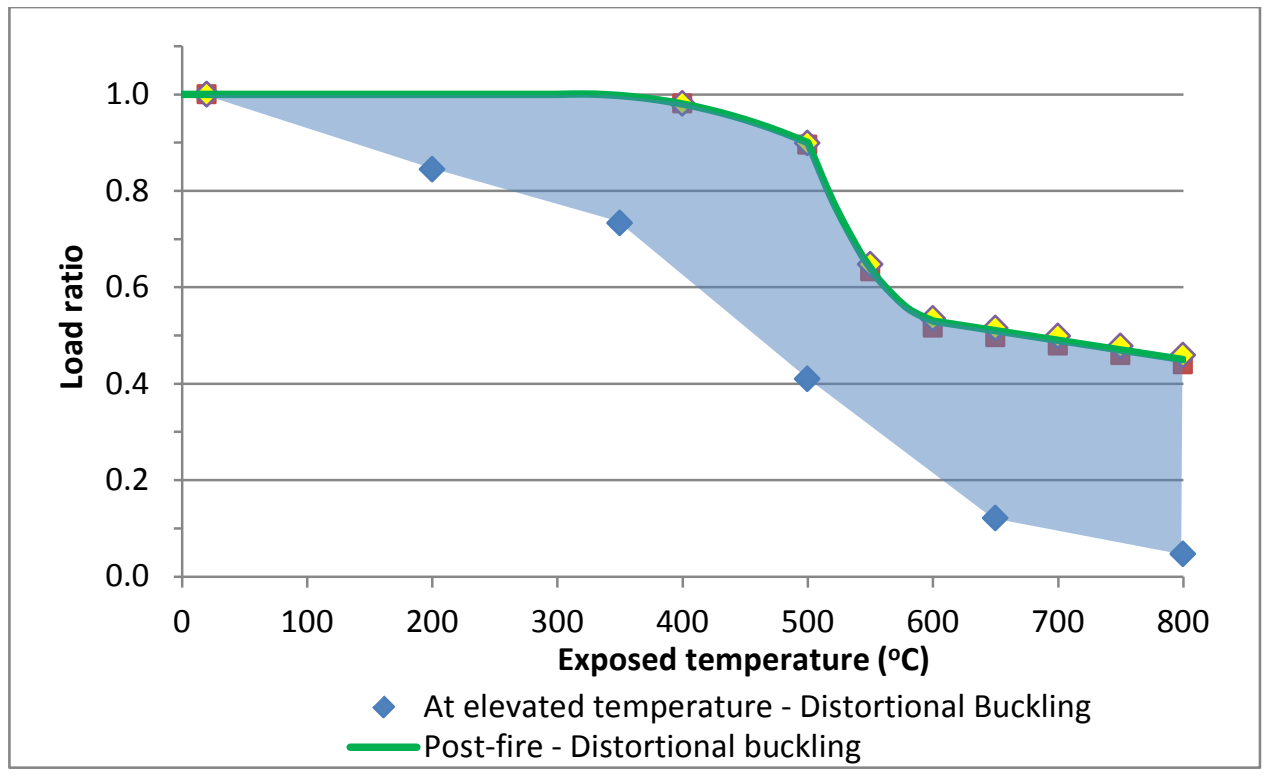

(b) High grade steel columns

Figure 17: Recovered capacity regime 